\title{
Strategies to Prevent Healthcare-Associated Infections through Hand Hygiene
}

\author{
Katherine Ellingson, PhD; ${ }^{1, \mathrm{a}}$ Janet $\mathrm{P}$. Haas, PhD, RN, CIC; ${ }^{2, a}$ Allison E. Aiello, PhD; ${ }^{3}$ Linda Kusek, MPH, RN, CIC; ${ }^{4}$ \\ Lisa L. Maragakis, MD, MPH; ${ }^{5}$ Russell N. Olmsted, MPH, CIC; ${ }^{6}$ Eli Perencevich, MD, MS; ${ }^{7,8}$ Philip M. Polgreen, MD; ${ }^{7}$ \\ Marin L. Schweizer, PhD; ${ }^{7,8}$ Polly Trexler, MS, CIC; ${ }^{5}$ Margaret VanAmringe, MHS; ${ }^{4}$ Deborah S. Yokoe, MD, MPH ${ }^{9}$
}

\section{PURPOSE}

Previously published guidelines provide comprehensive recommendations for hand hygiene in healthcare facilities. ${ }^{1,2}$ The intent of this document is to highlight practical recommendations in a concise format, update recommendations with the most current scientific evidence, and elucidate topics that warrant clarification or more robust research. Additionally, this document is designed to assist healthcare facilities in implementing hand hygiene adherence improvement programs, including efforts to optimize hand hygiene product use, monitor and report back hand hygiene adherence data, and promote behavior change. This expert guidance document is sponsored by the Society for Healthcare Epidemiology of America (SHEA) and is the product of a collaborative effort led by SHEA, the Infectious Diseases Society of America (IDSA), the American Hospital Association (AHA), the Association for Professionals in Infection Control and Epidemiology (APIC), and The Joint Commission, with major contributions from representatives of a number of organizations and societies with content expertise. The list of endorsing and supporting organizations is presented in the introduction to the 2014 updates. $^{3}$

\section{SECTION 1: RATIONALE AND STATEMENTS OF CONCERN}

I. For more than 150 years, the association between hand hygiene improvement and healthcare-associated infection (HAI) reduction has been demonstrated in a variety of settings, and hand hygiene is widely accepted as a foundational component of infection prevention and control programs. ${ }^{4-7}$ The proliferation and widespread use of alcoholbased hand sanitizers in the past decade has improved staff ability to conveniently and comfortably sanitize hands at frequent intervals. ${ }^{8-10}$ Yet adherence to recommended hand hygiene practices remains low (approximately 40\%), even in well-resourced facilities. ${ }^{11}$ Reasons for low hand hygiene adherence include inconvenient location of sinks, understaffing or busy work setting, and skin irritation as well as cultural issues, such as lack of role models and inattention to guidelines. ${ }^{12,13}$

II. Since publication of the Centers for Disease Control and Prevention (CDC) guidelines in $2002^{1}$ and the World Health Organization (WHO) guidelines in 2009, ${ }^{2}$ hand hygiene studies have been published that can inform various controversial issues. These issues-including pathogen-specific efficacy of products (eg, efficacy of alcohol against Clostridium difficile and norovirus), integration of glove use and hand hygiene protocols, and deficiencies in hand hygiene technique-warrant attention in the context of updated literature.

III. The 2009 WHO guidelines were accompanied by an extensive document linking recommendations with improvement strategies, yet evidence-based improvement programs have not been consistently implemented in the United States. ${ }^{14-16}$

A. There are an abundance of tools and methods for monitoring and reporting hand hygiene adherence, from direct observation to volume-based measurement to emerging automated oversight technologies. ${ }^{17-20}$ No national standards for measurement exist, and guidance on optimal implementation of measurement and feedback programs is needed.

B. Historically, the quality of studies evaluating the implementation of hand hygiene improvement programs was suboptimal, resulting in little evidence-based guid-

Affiliations: 1. Centers for Disease Control and Prevention, Atlanta, Georgia; 2. Westchester Medical Center and New York Medical College Department of Medicine, Valhalla, New York; 3. Gillings School of Global Public Health, University of North Carolina, Chapel Hill, North Carolina; 4. The Joint Commission, Oakbrook Terrace, Illinois; 5. Johns Hopkins University School of Medicine, Baltimore, Maryland; 6. St. Joseph Mercy Health System, Ann Arbor, Michigan; 7. Carver College of Medicine, University of Iowa, lowa City, Iowa; 8. Iowa City Veterans Administration Healthcare System, Iowa City, Iowa; 9. Brigham and Women's Hospital and Harvard Medical School, Boston, Massachusetts; a. These authors contributed equally to this work.

Received April 15, 2014; accepted May 2, 2014; electronically published July 16, 2014. Infect Control Hosp Epidemiol 2014;35(8):937-960

(C) 2014 by The Society for Healthcare Epidemiology of America. All rights reserved. 0899-823X/2014/3508-0002\$15.00. DOI: 10.1086/677145 


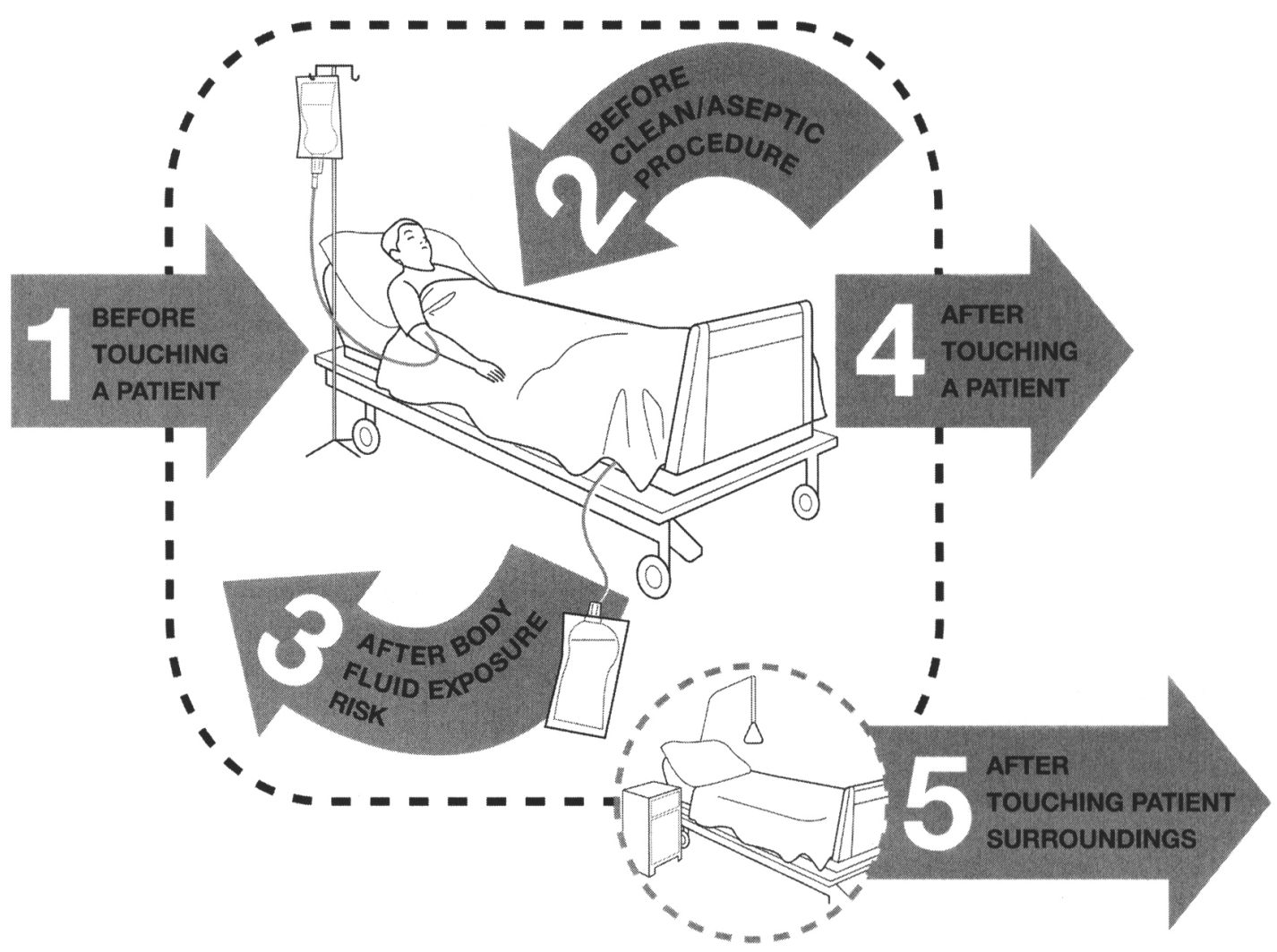

FIGURE 1. World Health Organization's 5 Moments for Hand Hygiene in acute care settings. Reproduced, with permission of the publisher, from "Five Moments for Hand Hygiene," World Health Organization, 2009, http://www.who.int/gpsc/tools/Five_moments/en/, accessed January 2014. All rights reserved.

ance. ${ }^{21}$ More recently, some multifactorial interventions have shown promise, and collective evidence suggests that specific bundles of interventions are effective in improving hand hygiene adherence. ${ }^{22}$

\section{SECTION 2: BACKGROUND-STRATEGIES}

\section{TO MEASURE HAND HYGIENE ADHERENCE}

\section{Defining opportunities}

A. To measure hand hygiene adherence, the opportunities for hand hygiene must be defined in clear and measurable ways. The most commonly recognized framework for measuring hand hygiene opportunities is the WHO's 5 Moments for Hand Hygiene (Figure 1). ${ }^{2}$ These moments include the many indications for hand hygiene defined in the CDC and WHO guidelines (Table 1) summarized into "moments" to promote clarity in education and measurement. The 5 moments include the following:

1. Moment 1: before touching the patient, to prevent colonization of the patient with healthcare-associated microorganisms

2. Moment 2: before a clean/aseptic procedure, to prevent an HAI that could arise from the patient's endogenous microorganisms or microorganisms on healthcare personnel (HCP) hands or in the environment

3. Moment 3: after body fluid exposure, to reduce the risk of colonization or infection of HCP and to reduce the risk of transmission of microorganisms from a colonized site to a clean site on the same patient

4. Moment 4: after touching the patient, to minimize the risk of transmitting microorganisms to the healthcare environment and to protect HCP by reducing contamination on their hands

5. Moment 5: after touching patient surroundings, as hand contact with patient objects (eg, linens, equipment) is associated with hand contamination

II. Variation in hand hygiene opportunities observed

A. Some organizations teach the concepts of the 5 moments but simplify measurement by observing hand hygiene opportunities only before and after care (ie, the entry and exit method). ${ }^{23}$ Many institutions in the United States have, for communication and assessment purposes, compressed the number of hand hygiene opportunities to entry to and exit from a patient care area, which roughly corresponds with the WHO's moment 1 and moment 4 or 5 . Although there is some concern that this leaves out moment 2 (before an aseptic pro- 
TABLE 1. Summary of Recommended Indications for Routine (ie, Excluding Surgical Prep) Hand Hygiene from the Centers for Disease Control and Prevention (CDC) Guidelines and the 2009 World Health Organization (WHO) Guidelines on Hand Hygiene in Health Care

\begin{tabular}{|c|c|c|}
\hline & CDC guidelines ${ }^{\mathrm{a}, \mathrm{b}}$ & WHO $(2009)^{b}$ \\
\hline \multicolumn{3}{|l|}{$\begin{array}{l}\text { Wash hands with either nonantimicrobial or antimicrobial soap and water } \\
\text { in the following clinical care situations }\end{array}$} \\
\hline When hands are visibly soiled & $\mathrm{Y}(\mathrm{IA}), \mathrm{HH}-2002$ & $\mathrm{Y}(\mathrm{IB})$ \\
\hline After known or suspected exposure to Clostridium difficile & Y (II), ISO-2007 & Y (IB, during outbreaks) \\
\hline $\begin{array}{l}\text { After known or suspected exposure to patients with infectious diarrhe } \\
\text { during norovirus outbreaks }\end{array}$ & Y (II), NV-2011 & ND \\
\hline If exposure to Bacillus anthracis is suspected or proven & $\mathrm{Y}$ (II) $\mathrm{HH}-2002$ & $\begin{array}{l}\text { Y (IB, spore-forming } \\
\text { organisms) }\end{array}$ \\
\hline \multicolumn{3}{|l|}{$\begin{array}{l}\text { Decontaminate hands with alcohol-based hand rub (preferentially) or } \\
\text { soap and water (alternatively) in the following situations }\end{array}$} \\
\hline Before direct patient contact & $\mathrm{Y}(1 \mathrm{~B}), \mathrm{HH}-2002$ & $\mathrm{Y}(\mathrm{IB})$ \\
\hline Before handling medication & ND & $\mathrm{Y}(\mathrm{IB})$ \\
\hline Before donning sterile gloves to insert an invasive device & Y (IB), HH-2002 & Y (IB, before handling) \\
\hline $\begin{array}{l}\text { Before and after handling respiratory devices, urinary catheters, and } \\
\text { intravascular catheters (palpating, replacing, accessing, repairing, } \\
\text { or dressing) }\end{array}$ & $\begin{array}{l}\text { Y (IA), PNEU-2003 } \\
\text { Y (IB), CAUTI-2009 } \\
\text { Y (IB), BSI-2011 }\end{array}$ & Y (IB, before handling) \\
\hline After direct patient contact & $\mathrm{Y}(\mathrm{IB}), \mathrm{HH}-2002$ & $\mathrm{Y}(\mathrm{IB})$ \\
\hline After removing gloves & $\mathrm{Y}$ (IB), HH-2002 & $\mathrm{Y}(\mathrm{IB})$ \\
\hline $\begin{array}{l}\text { After contact with blood, body fluids, mucous membranes, nonintact } \\
\text { skin, and wound dressings if hands not visibly soiled }\end{array}$ & $\begin{array}{l}\text { Y (IA), HH-2002 } \\
\text { Y (1A), PNEU-2003 }\end{array}$ & $\mathrm{Y}(\mathrm{IA})$ \\
\hline $\begin{array}{l}\text { After contact with inanimate objects in the patients' immediate } \\
\text { environment }\end{array}$ & $\mathrm{Y}(\mathrm{II}), \mathrm{HH}-2002$ & $\mathrm{Y}(\mathrm{IB})$ \\
\hline If moving from a contaminated body site to a clean body site & $Y(I I)$ & $\mathrm{Y}(\mathrm{IB})$ \\
\hline
\end{tabular}

${ }^{a}$ Includes published guidelines from the CDC on hand hygiene (HH-2002), isolation precautions (ISO-2007), management of norovirus outbreaks in healthcare (NV-2011), prevention of catheter-associated urinary tract infections (CAUTI-2009), prevention of pneumonia in healthcare settings (PNEU-2003), and prevention of intravascular catheter-related infections (BSI-2011).

${ }^{b} \mathrm{Y}$, yes; N, no; ND, not discussed. Designations as IA, IB, and II refer to CDC and WHO use of the following evidence grades: IA, strongly recommended for implementation and strongly supported by well-designed experimental, clinical, or epidemiological studies; IB, strongly recommended for implementation and supported by certain experimental, clinical, or epidemiologic studies and a strong theoretical rationale; and II, suggested for implementation and supported by clinical or epidemiologic studies or a theoretical rationale.

cedure) and other opportunities for contamination within the patient care encounter, ${ }^{20,24-27}$ there is some evidence that the entry and exit method may be an adequate proxy for measurement of hand hygiene for the entire patient encounter. ${ }^{23,28}$ Operationally, the entry and exit method is easier to institute for measurement purposes and respects patient privacy. ${ }^{23,29}$ Emphasis on moment 1 and moment 4 (or 5) also highlights the priority for reducing cross-transmission of pathogens in health care.

B. Canada has a national hand hygiene campaign built on the WHO implementation materials but modified the WHO's 5 moments into 4 moments by combining moments 4 and 5 into "after patient/patient environment contact." Of note, Canada's version of moment 1 is "before initial patient/patient environment contact."

C. The CDC's protocol for multidrug-resistant organism and $C$. difficile infection (CDI) surveillance includes hand hygiene measurement as a "supplemental prevention process measure." For simplification of measurement, the protocol stipulates observation of hand hygiene opportunities after healthcare personnel con- tact with a patient or with inanimate objects in the vicinity of the patient (moments 4 and 5 only). ${ }^{31}$ Monitoring hand hygiene on exit from a patient room (or after care) is convenient for observers because the indication for hand hygiene is obvious. A recent study found that, among US Veterans Affairs hospitals, hand hygiene on exiting a patient room was the most common opportunity to be routinely monitored. ${ }^{32}$

III. Methods for hand hygiene adherence measurement

A. The main hand hygiene measurement methods are direct observation, indirect volume or event count measurement, and advanced technologies for automated adherence monitoring. Each method has strengths and weaknesses (Table 2). Using multiple methods to measure hand hygiene is a way to address the strengths and limitations associated with a single-measurement approach. ${ }^{19,20,33-36}$ Gould et $\mathrm{al}^{35}$ recommended that the feasibility and acceptability of a combined approach should be explored with further studies to refine the method.

B. In the United States, there is no national standard for hand hygiene adherence measurement, in part because 
TABLE 2. Summary of Observations for Hand Hygiene Adherence Measurement, Including Strengths and Weaknesses

\begin{tabular}{lc}
\hline Observation method & Strengths \\
\hline Direct observation $^{14,20,25,35,134}$ & Gold standard for hand hygiene adherence \\
Only method that can discern all opportu- \\
nities for hand hygiene within patient \\
care encounter and assess hand hygiene \\
technique \\
Allows for immediate corrective feedback \\
Use of technology (eg, tablet) to save data \\
entry step or to assist observer in stan- \\
dechnology-assisted direct \\
observation ${ }^{43-50}$ \\
subjectivity) \\
Video-assisted observations can provide as- \\
sessment of all or most opportunities to \\
be analyzed at remote location \\
Less time-consuming and costly than direct \\
observation \\
Product volume or event count \\
measurement ${ }^{2,20,25,35,54,63}$ \\
Not subject to Hawthorne effect and selec- \\
tion or observer bias \\
Unobtrusive and encompasses all \\
opportunities \\
Counters can detect changes in frequency \\
of use according to time of day or pat- \\
terns of use in a hospital unit \\
May assist in optimal location of \\
dispensers
\end{tabular}

Advanced technologies for automated monitoring ${ }^{32,42,72-78}$

Self-report ${ }^{2,20,25,255,256}$
Systems with wearable components can provide positive feedback or just-in-time reminders to perform hand hygiene and individual-level monitoring

Captures all episodes entering and leaving a patient zone (eliminating selection and observer bias) and associated adherence

Can raise individuals' awareness of their practice
Labor intensive and costly

Observers must be trained and validated

Subject to Hawthorne effect

Subject to selection and observer bias

Requires investment and maintenance of infrastructure

Video monitoring requires trained observers, has limited opportunity for immediate feedback, and has potential to impact patient privacy

Relies on accurate usage data, which may be compromised by system gaps or intentional tampering

Cannot distinguish hand hygiene opportunities (no denominator) or who used the product

Cannot assess adequacy of technique

There are significant costs associated with event counting systems, and ongoing maintenance is required

Expensive to implement and requires ongoing maintenance (eg, battery replacement or recharging) for all devices

Difficult to detect opportunities within the patient encounter or to assess technique

Concerns about healthcare worker privacy

Limited data outside of research settings

Unreliable as healthcare personnel overestimate their performance; should not be used for hand hygiene monitoring data the optimal methods for measurement are still evolving. Furthermore, many technological innovations to help facilitate and standardize hand hygiene adherence monitoring are still under evaluation in terms of validity and acceptability. ${ }^{37}$ Wide variation in hand hygiene observation methods makes it difficult to compare adherence rates across organizations.

IV. Direct observation

A. Direct observation includes in-person monitoring of hand hygiene behavior. To enhance validity and reliability of direct observation, it is crucial that observers are trained and that their observations are validated initially and at intervals to ensure accuracy; a suite of tools was developed by the WHO to help standardize the observation process. ${ }^{18}$ To minimize the Hawthorne effect, or behavior change based on the awareness of subjects that they are being observed, ${ }^{35,38}$ some facilities have used covert observers, or "secret shoppers." 39,40 Although use of covert observers may improve the validity of the measurement and be appropriate for quality improvement initiatives, some experts have raised ethical concerns about avoiding informed consent of those being observed; furthermore, it is unlikely that the covert nature of the observations can be sustained. ${ }^{34,41}$

B. Some protocols direct observers to provide direct feedback for noncompliant observations ${ }^{23}$ (ie, "just-in-time training") or to document the names of noncompliant individuals, ${ }^{42}$ making the observation part of the intervention. This is appropriate to the goal of increasing hand hygiene, but adherence is likely to be inflated by 
the presence of an observer who is collecting names or giving feedback.

C. Observer and selection bias are the systematic inclusion of selected opportunities (eg, nurses focusing on the behavior of physicians and vice versa or only observing certain shifts), which may be minimized by randomizing audit times and directing observers to observe a minimum number of opportunities across HCP types. ${ }^{17}$

D. There is no accepted standard stipulating the number and distribution of hand hygiene opportunities that facilities or units should observe. ${ }^{32}$ Poor hand hygiene is likely to be revealed with fewer observations. Observing good adherence in a very small sample of opportunities, however, is less reassuring. Reports of hand hygiene adherence are often called into question because of the perceived inadequacy in number or representativeness of observations to reflect true adherence. ${ }^{25,43}$ A study documenting every entry and exit opportunity over a 14-day period found that a simulated observer placed in the ward for 1 hour could have observed a very small number of opportunities; however, if simulated observers switched locations every 15 minutes, more opportunities and a greater diversity of HCP could be observed. ${ }^{43}$ Another study showed that observers placed at a greater physical distance from the observed hand hygiene opportunities made more errors, as did observers on wards with higher activity levels. ${ }^{44}$

V. Technology-assisted direct observation

A. Technology-assisted direct observation includes use of mobile devices or video monitoring to document hand hygiene adherence.

B. In-person direct observation can be streamlined using a mobile handheld device rather than paper and pen to capture adherence data. Commercially available programs like iScrub for iOS mobile devices ${ }^{29,45}$ can be used, or an application for a mobile device can be developed in house $e^{4-48}$ to help standardize data collection. Use of these devices requires substantial investment by healthcare institutions or the use of personal rather than institutional devices for hand hygiene observations. Electronic devices must be maintained and charged and are subject to loss.

C. Another variation on technology-assisted direct observation is video monitoring, in which recording equipment is covertly aimed at a sink or alcohol-based hand rub (ABHR) dispenser and continuously records opportunities for hand hygiene across all shifts and classes of HCP. ${ }^{49-51}$ The video is later reviewed by trained auditors to assess hand hygiene in the same manner as in-person directly observed hand hygiene surveillance. A third-party remote video auditing service can utilize web-based applications to provide adherence feedback, although there is no opportunity for immediate feedback when the review takes place remotely, and patient privacy can be impacted by these systems even with narrowly focused cameras. ${ }^{52}$

VI. Indirect hand hygiene adherence through volume or event count measurement

A. Product usage (soap, ABHR) or dispenser use is an indirect measurement of hand hygiene adherence $\mathrm{e}^{14,25,53}$ and can be used to monitor trends in consumption over time or by type of care unit. ${ }^{35,36,54}$ This can be as simple as tracking the amount of product used by individual units over time. Product usage can also be compared with the industry-average volume of a single dose of product in estimating adherence rates. ${ }^{36,55,56}$ Product measurement can be hampered by unreliable usage data from distribution or materials management or intentional tampering with dispensers or deliberate waste of product.

B. There are also advanced dispenser-based counters that create a date and time stamp each time the dispenser is used. ${ }^{35,37,54,57-66}$ Counting devices can also be fitted into personal dispensers of ABHR worn on the body to increase convenience of hand hygiene. ${ }^{67}$ In some studies, increased use of ABHR was associated with an increase in observed hand hygiene adherence; ${ }^{68-71}$ however, not all studies have found such an association. ${ }^{36,54,72}$ Automated dispenser counting systems may cost upward of $\$ 30,000-\$ 40,000$ USD per patient care unit, and data must be manually downloaded from the counters if an automatic web-based download via Wi-Fi is not used. ${ }^{73}$ In addition, counters must be monitored for low battery signals and disappearance. ${ }^{63,74}$

VII. Advanced technologies for automated monitoring of hand hygiene adherence

A. "Intelligent" hand hygiene systems are being developed with the idea that the system should have a wearable/ mobile component, record all hand hygiene opportunities, provide a feedback or reminder system, and, ideally, respond to HCP behavior and actions. ${ }^{74}$ Sensor networks are designed to sense when HCP enter a patient care area, such as a room or bedside; detect when hand hygiene is performed; and, if hand hygiene is not performed, remind the healthcare worker to do so. ${ }^{75}$ Older networks used light beams and motion sensors ${ }^{76}$ along with audible tones, ${ }^{77}$ worded voice prompts, ${ }^{76,78}$ or flashing lights ${ }^{77}$ to remind HCP to clean their hands. Sensors installed at a hospital ward entrance provided an audible reminder for visitors and staff when triggered via motion sensor; overall hand hygiene adherence at the threshold of the unit rose from $7.6 \%$ to $49.9 \%{ }^{79}$ when this system was in use.

B. Newer systems use personal wearable electronic monitors that communicate with ceiling-mounted infrared emitters, or they use Wi-Fi or radio frequency signals to establish defined zones around patient beds or at the threshold of patient rooms. These systems usually capture entry and exit into a patient zone (Figure 2), com- 


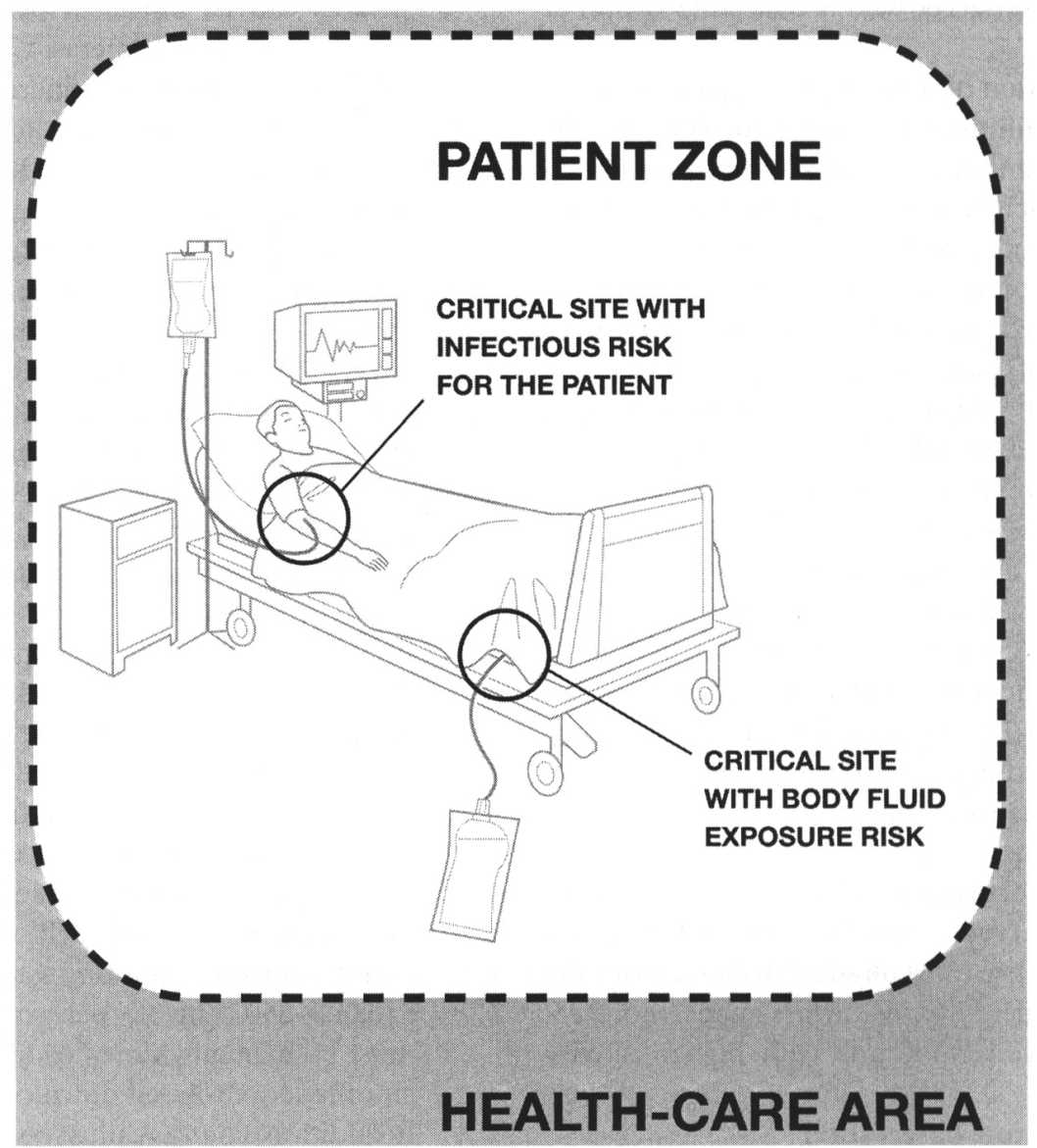

FIGURE 2. Patient zone defined to assist in teaching healthcare personnel about indications for hand hygiene. Reproduced, with permission of the publisher, from "WHO Guidelines on Hand Hygiene in Health Care," Figure I.21.5a, p. 122, World Health Organization, http:// whqlibdoc.who.int/publications/2009/9789241597906_eng.pdf?ua=1, accessed January 2014. All rights reserved.

parable to WHO moments 1 and 4 , but are less successful at capturing WHO moments 2 and 3 within the patient care episode. They cannot distinguish whether the healthcare provider touched the patient or only touched the environment (WHO moment 5). Studies have shown some systems to be comparable to direct observation, with error rates of less than $10 \%$ compared with direct observation. ${ }^{80,81}$ A system developed using active, battery-powered devices that communicate over unused space in the Wi-Fi spectrum to generate sensor contact logs and event time stamps for inference of hand hygiene adherence noted $97 \%$ sensitivity and 100\% specificity. ${ }^{82}$ Another recently developed technology uses a credit card-sized alcohol sensor badge to detect whether a healthcare worker performs hand hygiene with an alcohol-based product: if alcohol is detected within 8 seconds of room entry or exit, the badge responds with a green light and an audible ping; if not, the badge shows red and beeps. ${ }^{83}$

C. Using automated systems eliminates the selection and recall bias of human observers and provides a just-in- time reminder that allows HCP to correct hand hygiene errors before they reach the patient. However, there are few studies that describe successful widespread use of these systems. Common issues include dead batteries in recording units, nonoperating dispensing units, and recording errors (ie, room entry capture when entry was made into a nontriggered room adjacent to a triggered room). ${ }^{84}$ In a recent study, a system that performed well in a research setting was only able to accurately identify hand hygiene opportunities on entry and exit about half the time in a clinical setting. ${ }^{85}$

D. Tracking systems require wearable devices, sensors, and triggers, all of which must be purchased or reclaimed (ie, old pagers destined for disposal). ${ }^{82}$ Systems requiring hardwiring or construction add to the cost of installation and potentially increase the risk of infection from particulates like mold or fungus released during installation. ${ }^{86}$ Wireless frequencies must also take into account the unit and bed layout and the potential to interfere with other hospital equipment dependent on Wi-Fi. ${ }^{37}$ Sensor networks record hand hygiene events 
only within a defined care area and cannot capture events that occur at distance, which makes continuous monitoring of transient HCP problematic. ${ }^{80}$

E. Hand hygiene reminder systems that use audible tones or voice alerts may disturb patients ${ }^{87}$ or be annoying or distracting to HCP. HCP expressed a preference for a badge vibration prompt rather than an audible reminder that other staff or patients may hear, ${ }^{88}$ though vibration shortens battery life compared with light or sound. Healthcare worker privacy may also be a concern, especially in individual-level monitoring. HCP noted that they did not mind being monitored or watched via electronic monitoring but wanted a period of time without monitoring to become accustomed to any monitoring device. ${ }^{87}$ However, a survey of $89 \mathrm{HCP}$ in structured focus groups revealed significant concerns about the accuracy of automated hand hygiene adherence data and possible punitive use of adherence data. ${ }^{89}$ $\mathrm{HCP}$ are also concerned about wearing another device when they already have a pager or pagers, phone, radiation badge, and so on and suggested that a hand hygiene monitoring system be incorporated into existing devices. ${ }^{87}$

\section{SECTION 3: BACKGROUND-STRATEGIES}

\section{TO PREVENT HAI THROUGH HAND}

\section{H Y G I E N E}

I. Existing guidelines and recommendations for hand hygiene

A. Nationally and internationally recognized guidelines dedicated to hand hygiene in healthcare settings include the 2002 CDC Guideline for Hand Hygiene in Healthcare Settings and the 2009 WHO Guidelines on Hand Hygiene in Health Care. ${ }^{1,2}$ The WHO guidelineswhich resulted from a multiyear international effort, including extensive review of more than 1,000 publications-were largely consistent with the CDC guidelines (Table 1).

B. Specific recommendations for hand hygiene also appear in other CDC guidelines, including the 2007 Guidelines for Isolation Precautions, ${ }^{90}$ the 2011 Guideline for the Prevention and Control of Norovirus Gastroenteritis Outbreaks in Healthcare Settings, ${ }^{91}$ and other guidelines for the prevention of specific device- and procedureassociated HAIs. ${ }^{92-94}$ These recommendations should be embedded in individual facility policies and procedures.

C. While there are numerous strong (1A and $1 \mathrm{~B}$ ) recommendations in the CDC and WHO guidelines, few are based on randomized trials or epidemiologically rigorous observational studies. This lack of rigor occurs in part because of ethical considerations in randomizing control groups and in part because investment in the science behind hand hygiene has lagged behind other healthcare research topics.
II. Clarifications and updates to the literature

A. Hand hygiene product efficacy

1. Efficacy versus bacteria

a. Several studies have been conducted to compare the relative efficacy of various hand hygiene products against bacteria. In the majority of studies, ABHRs (with alcohol concentrations between $62 \%$ and $95 \%)$ are described as being more effective than either plain or antimicrobial soaps over a broad range of testing conditions. There are 13 clinical studies of hand hygiene product efficacy against bacteria that compare $A B H R$ with soap products in use by HCP. Of these, 12 report ABHR to be superior to soap formulations, ${ }^{95-104}$ and 1 reports equivalence of ABHR with soap products; ${ }^{105} 3$ of these studies were published after publication of CDC and WHO guidelines. Product efficacy relative to $C$. difficile is discussed in further detail below.

b. One issue of concern is that study conditions may not always be reflective of clinical situations because artificial contamination with microorganisms and controlled hand hygiene regimens are sometimes used.

2. Efficacy versus viruses

a. The majority of available studies show that ABHRs have significantly better efficacy in removing several different viruses than nonantimicrobial and antimicrobial soap and water, ${ }^{106-115}$ suggesting that ABHRs are likely to provide some protection against several respiratory and enteric viruses on the hands.

b. Overall, there are fewer studies of various hand hygiene products against viruses. In addition, many of the studies have small sample sizes and rely on artificial contamination with a virus or a surrogate virus. More research is needed to identify the best formulations for inactivation of viruses on the hands of HCP. Product efficacy relative to norovirus is discussed in further detail below.

3. Efficacy based on dispensing mechanism

a. The 2002 CDC guidelines stated that alcohol-containing hand wipes were not a substitute for gel or foam ABHRs, on the basis of inferior efficacy. ${ }^{1}$ Since that time, alcohol-containing wipes have been reported to have similar efficacy to ABHR gel and foam against influenza virus. It appears that some formulations of alcohol-based wipes with at least $65 \%$ alcohol are now comparable to alcohols delivered by other dispensing methods. ${ }^{116}$

b. Alcohol-containing hand wipes offer a convenient option for bed-bound patients, first responders, and others who cannot easily get to sinks or wallmounted dispensers.

\section{B. Technique}

1. Until recently, scientific literature was scant with regard to hand hygiene technique. ${ }^{117-121} \mathrm{CDC}$ and WHO 
guidelines provide general guidance on technique and recommend that manufacturer guidance be followed for volume of hand hygiene product used and contact time of product. The minimum time required by manufacturers is generally $15-20$ seconds, with the volume required changing on the basis of the size of the hands to meet the time requirement.

2. Recent studies suggest that 15 seconds is insufficient for meeting standards for high-quality hand disinfection (EN 1500) ${ }^{122}$ and that physical coverage of hands with hand hygiene product in clinical settings is often substandard. ${ }^{13,119,120,123}$

3. In 2009 , the WHO published guidance on a standardized multistep technique to promote coverage of all surfaces of the hands with hand hygiene product, estimating 20-30 seconds for hand rubbing (http:// www.who.int/gpsc/5may/How_To_HandRub_Poster .pdf) and 40-60 seconds for hand washing with soap and water (http://www.who.int/gpsc/5may/How_To _HandWash_Poster.pdf). A publicly available video demonstrating these techniques is available on the New England Journal of Medicine website (http://www .nejm.org/doi/full/10.1056/NEJMvcm0903599). ${ }^{124}$

4. Recent studies have shown that training HCP on proper technique can increase coverage and decrease bacterial counts on the hands of HCP. ${ }^{12,119,120}$ Some studies have indicated that rigid adherence to standardized step-by-step technique may not be as critical by demonstrating that sufficient pathogen reductions could be achieved by instructing HCP simply to cover their hands with hand hygiene product (ie, the "reasonable application" approach) regardless of technique used. ${ }^{104,122}$ However, the studies finding reasonable application equivalent to a standardized technique had protocols using $3 \mathrm{~mL}$ of product, and it is unclear how often this volume is used in clinical practice $^{125}$ (due to longer drying times associated with use of higher volumes). ${ }^{126}$

5. The standard dispenser actuation for ABHRs is 1.1 $\mathrm{mL}$, although a recent study showed variability from 0.6 to $1.3 \mathrm{~mL}$ of product dispensed with each actuation. ${ }^{125}$ Two studies published in 2013 report conflicting findings on whether $1.1 \mathrm{~mL}$ is sufficient to meet the US Food and Drug Administration (FDA) requirement for $\log$ reductions. ${ }^{125,127}$

C. Tolerability

1. Irritant contact dermatitis (ICD) is the most frequently occurring adverse reaction to hand hygiene products. This condition impacts a large proportion of the nursing workforce at some point in their careers. ${ }^{128}$ Symptoms include dryness, irritation, itching, cracking, and bleeding. ${ }^{129}$ Factors associated with this condition include number of hand washes, product formulations, and seasonal weather variations. ${ }^{129,130}$ Strategies to prevent and manage ICD include the following: a. Have a process to manage HCP with ICD.

b. Involve staff members in hand hygiene product selection.

c. Educate HCP about the relative impact of $A B H R$ versus hand washing in terms of skin damage. ${ }^{131}$

d. Promote use of ABHR for routine hand hygiene. ABHRs are well tolerated and associated with less ICD than soap-and-water hand washing. ${ }^{2,132-137}$

e. Wash hands with warm or cold water. There is no evidence that warm water is superior to cold water, although tepid water may be better tolerated. Hot water, however, should be avoided because it can irritate the skin, leading to dermatitis and bacterial colonization. $^{138}$

f. Provide lotion for use in the workplace and encourage use. ${ }^{129,130,132,134,139}$ Because lotion can become contaminated, use nonrefillable containers or disposable bags of lotion in dispensers.

g. Promote use of gloves for wet work, which includes extensive patient care. Use of cotton glove liners when extended use of gloves is anticipated may help individuals with ICD to maintain healthy skin. ${ }^{132,140,141}$

2. Allergic contact dermatitis is much less common and may range from mild and localized (and thus difficult to differentiate from ICD) to severe generalized symptoms, including respiratory distress and anaphylaxis. ${ }^{129}$

a. For HCP with immediate, generalized, or respiratory distress, refer to the occupational health department or emergency department as appropriate to the situation.

b. HCP who suffer from localized symptoms that are severe or that persist despite attempts to moisturize may have an allergy to 1 or more elements of the hand hygiene product. The most common causes of these allergies is the fragrance, preservative, or antiseptic agent.

c. Referral to an allergist may be appropriate, where patch testing can be performed. In studies that patch tested nurses using new ABHR products or self-identifying as allergic to ABHR, authors have concluded that allergic reactions to ABHRs are rare, may be due to other components of the product, and may be transient. ${ }^{131,142}$

d. Alternate product options should be available for individuals who are sensitive to the hand hygiene products used by their facility. ${ }^{129}$

D. Toxicity and fire risk

1. Cognitively impaired, behavioral health, or substance abuse patients may be injured by ingestion of ABHR. A point-of-care risk assessment can help guide placement of dispensers or decision to use nontoxic hand hygiene products.

2. ABHRs are flammable and must be installed and 
stored in accordance with fire regulations. ABHRs are widely used and are safe when used in accordance with these regulations. ${ }^{143,144}$

E. Integration of glove use into routine hand hygiene protocols

1. Both hand hygiene and glove use are strategies to prevent transmission of HAIs through hand contact, but recommendations concerning glove use are often segregated in other guidelines on isolation and personal protective equipment..$^{90}$ In the context of patient care, it makes sense to think of glove use and hand hygiene as related elements of a comprehensive strategy to prevent transmission.

2. The CDC and WHO recommend putting on singleuse, disposable gloves for the following indications: ${ }^{2,90,145}$

a. Before an aseptic procedure

b. When anticipating contact with blood or bodily fluid

c. When in contact with a patient or patient equipment/environment during contact precautions

3. The CDC and WHO recommend taking off gloves for the following indications:

a. If gloves are damaged and integrity is suspected to be compromised

b. When contact with blood, body fluid, nonintact skin, or mucous membranes has ended

c. When contact with a single patient and his or her surroundings or a contaminated body site on a patient has ended

d. When there is an indication for hand hygiene

4. To minimize contamination when putting on and taking off gloves, the WHO suggests the following: ${ }^{.45}$

a. When putting on gloves, take only 1 glove out of the box at a time, touching only the top of the cuff.

b. When taking off gloves, pinch 1 glove at wrist level without touching the forearm and peel away from the hand such that glove turns inside out. Hold the removed glove in the gloved hand and slide the fingers of the bare hand between the glove and wrist and remove the glove by rolling it down the hand and folding it into the first glove.

F. Prospective studies have shown that glove use reduces transmission of CDI and carriage of VRE on healthcare worker hands. ${ }^{16,147}$ Because several studies have shown that hands can become contaminated during glove removal, hand hygiene is recommended after removing gloves. ${ }^{147-151}$

G. Hand hygiene before donning nonsterile gloves

1. $C D C$ guidelines emphasize hand hygiene relative to patient contact or contact with patient surroundings. If a healthcare worker prepares for direct patient contact requiring gloves, he or she should perform hand hygiene per the before-patient-contact recommendation..$^{2,134,145}$ The WHO's glove use information leaf- let more explicitly states that "when an indication for hand hygiene precedes a contact that also requires glove usage, hand rubbing or hand washing should be performed before donning sterile gloves." ${ }^{145}$ This wording has led some facilities to mandate hand hygiene immediately before nonsterile glove use. However, the indication was intended to relate to the patient contact rather than the act of donning gloves.

2. Contamination of unused gloves in boxes is one concern motivating institution-specific policies for hand hygiene before nonsterile glove use. An early study showed that gloves in boxes were not subject to significant contamination throughout duration of box use, regardless of the duration of time that the boxes were open. ${ }^{152}$ However, researchers in an orthopedic ward in New Zealand found contamination of $13.2 \%$ of unused nonsterile gloves with potential pathogens, albeit in low numbers, ${ }^{153}$ suggesting that hand hygiene before reaching for gloves or a different design for glove boxes may be important.

3. Controversy has persisted about the need for hand hygiene prior to donning nonsterile gloves. A 1995 study found that there was no significant difference in colony-forming units on healthcare worker hands between the group that washed hands and examined patients with bare hands compared with the group that donned gloves with or without prior hand washing. ${ }^{154}$ Similarly, a 2013 study reported no significant difference in glove contamination between groups that did and did not sanitize hands prior to donning gloves. ${ }^{155}$

H. Triclosan

1. A range of hand hygiene products containing triclosan has been heavily marketed in consumer and healthcare settings. The widespread use of triclosan antibacterial soaps and body washes in the consumer market has become controversial because of nonsuperior effectiveness in preventing disease relative to plain soap. ${ }^{156,157}$

2. The US FDA recently issued a proposed rule requiring manufacturers to provide more substantial data to demonstrate the safety and effectiveness of antimicrobial soaps marketed to consumers. ${ }^{158,159}$ While this rule does not apply to healthcare settings, there are few data to suggest that triclosan-containing soaps are superior to standards of care, including chlorhexidine soap and ABHR, in healthcare settings. In the 1990s, 2 small studies showed that use of triclosan soap for hand washing correlated with eradication of methicillin-resistant Staphylococcus aureus in neonatal settings, ${ }^{160,161}$ and these studies were cited as evidence of clinical effectiveness in a 2000 industry-sponsored review finding triclosan to be safe and effective in healthcare settings. ${ }^{162}$ However, a 2008 study found significant reductions in nosocomial infections among high-risk neonates when switching from tri- 
closan hand washing to hand hygiene protocols using chlorhexidine soap and ABHRs. ${ }^{163}$ Similarly, a 2005 study showed significant reductions in multidrugresistant organisms following the introduction of ABHR to a setting that previously used triclosan soap. ${ }^{187}$ Furthermore, recent studies suggest that triclosan exposure can lead to resistance, particularly for Pseudomonas aeruginosa. ${ }^{164,165}$ Finally, a 2014 study found that the presence of triclosan in the nasal cavities of healthy adults was associated with $S$. aureus nasal colonization, suggesting that the impact of triclosan on the microbiome is potentially important and warrants further investigation. ${ }^{166}$

3. Understanding the incremental clinical benefit of triclosan use in healthcare settings is important because of its potential costs in terms of environmental and individual exposure risks. Triclosan is a known water contaminant, and concerns persist about endocrine disruption in aquatic life, ${ }^{167}$ which has led to inquiries about exposure levels and health effects in humans. The 2003-2004 CDC National Health and Nutrition Examination Survey (NHANES) detected triclosan in $75 \%$ of urine samples from US adults and children. ${ }^{168}$ Further assessment of NHANES data revealed positive associations between triclosan levels in individuals and poor health indicators, such as altered thyroid hormone levels, elevated body mass index, and allergies. ${ }^{169-171}$ The public health significance of triclosan exposure requires further examination, but evidence to date combined with no clear benefit has concerned both scientists and regulators. ${ }^{172}$

4. In the absence of clear evidence suggesting superior effectiveness in healthcare settings, combined with risks of resistance and contamination, use of triclosan-containing soaps in healthcare settings for hand hygiene should be avoided.

I. Hand hygiene and norovirus prevention

1. There has been debate regarding the effectiveness of hand hygiene, particularly alcohol-based hand sanitizers, for reducing norovirus contamination on the hands.

2. There are conflicting results from in vivo studies comparing the efficacy of hand hygiene products on norovirus or their surrogates; 2 randomized studies have shown that alcohol-based hand sanitizers are significantly more effective than either plain soap wash or antibacterial soap washes. ${ }^{10,173}$ Two studies contradict these results, one of which was an observational study of norovirus and the other a randomized study that showed that water alone worked better than either alcohol-based hand sanitizer or antimicrobial soap. ${ }^{113}$ Several studies show that formulation, type, and percent of alcohol can significantly impact the efficacy of hand sanitizers against norovirus surrogates. ${ }^{107,108,110,173-177}$ The majority of available studies indicate that a range of $62 \%-95 \%$ ethanol is more effective than other concentrations or alcohol types. $\mathrm{CDC}$ guidelines do not discuss which products to use after caring for norovirus patients in routine settings. However, in addition to glove use as part of contact precautions, they do recommend use of soap and water for the care of patients with known, suspected, or proven norovirus infection during norovirus outbreaks, although this is based on "very low-quality evidence." ${ }^{\text {1 }}$

3. Although studies have indicated that povidone-iodine wash is superior to alcohol, ${ }^{108,110}$ it is not usually feasible to switch hand hygiene products for isolated cases of norovirus.

4. Given the low-quality and contradictory evidence combined with the sporadic nature of norovirus outbreaks, focus should be on stressing adherence to glove use and hand hygiene rather than on specific products or methods.

J. Hand hygiene and CDI prevention

1. The use of soap and water versus $A B H R$ for hand hygiene while caring for patients with CDI is controversial. The WHO and SHEA guidelines recommend preferential use of soap and water over ABHR for hand hygiene while caring for CDI patients in outbreak or hyperendemic settings. ${ }^{2,178}$ These recommendations are supported by studies showing soap and water to be more effective at removing $C$. difficile spores from the bare hands of volunteers than ABHR; ${ }^{179,180}$ these studies do not, however, provide evidence of the superiority of soap and water in a clinical setting.

2. Although in vivo studies demonstrate that $C$. difficile spores are resistant to alcohol, they also show poor log reductions (less than 2) for handwashing with soap and water; ${ }^{179,180}$ a 2013 study showed that only atypical products (eg, ink and stain remover) could remove more than 1 log. ${ }^{181}$ Findings from these investigations-combined with studies showing that wearing gloves is associated with decreased CDI transmission $^{146,182}$-are reflected in a recent CDC Vital Signs report on the epidemiology of CDI in the United States that includes the following: "Wear gloves and gowns when treating patients with $\mathrm{CDI}$, even during short visits. Hand sanitizer does not kill C. difficile, and hand washing may not be sufficient." 183

3. The relationship between hand hygiene methods and CDI rates over time is not definitive. A large study of a multimodal hand hygiene campaign showed significant decreases in CDI and MRSA associated with increased soap and ABHR consumption, ${ }^{184}$ but parsing out the role of $A B H R$ versus soap was impossible. Other longitudinal studies published in the past decade showed no association between increased ABHR use and rates of CDI while showing significant decreases on other rates of other HAIs. ${ }^{69,185-187}$ 
TABLE 3. Recommended Practices for Hand Hygiene in the Perioperative Setting ${ }^{198}$

\begin{tabular}{|c|c|c|}
\hline Preoperative hand preparation steps & $\begin{array}{l}\text { Traditional } \\
\text { surgical } \\
\text { scrub }\end{array}$ & $\begin{array}{l}\text { Surgical } \\
\text { alcohol-based } \\
\text { hand rub }\end{array}$ \\
\hline Remove all jewelry from hands and wrists, don surgical mask & $\mathrm{X}$ & $\mathrm{X}$ \\
\hline $\begin{array}{l}\text { Wash hands using either nonantimicrobial or antimicrobial soap to ensure that they are clean at } \\
\text { the beginning of the day; repeat soap-and-water hand wash anytime hands are visibly soiled }\end{array}$ & $\mathrm{X}$ & $\mathrm{X}$ \\
\hline $\begin{array}{l}\text { Use a nail pick or brush with running water at the beginning of the day to remove debris from } \\
\text { under the nails }\end{array}$ & $X$ & $X$ \\
\hline Ensure that hands are dry after hand wash & & $\mathrm{X}$ \\
\hline $\begin{array}{l}\text { Apply alcohol product to hands according to manufacturer's instructions: usually } 2 \text { or } 3 \text { applica- } \\
\text { tions of } 2 \mathrm{~mL} \text { each }\end{array}$ & & $\mathrm{X}$ \\
\hline $\begin{array}{l}\text { Rub hands to dry completely before donning sterile surgical gloves; do not wipe off the product } \\
\text { with sterile towels }\end{array}$ & & $X$ \\
\hline $\begin{array}{l}\text { After initial wash, wet hands and forearms under running water and apply antimicrobial agent } \\
\text { to wet hands and forearms using a soft, nonabrasive sponge according to the manufacturer's } \\
\text { directions; in general, the time required will be } 3-5 \text { minutes }\end{array}$ & $X$ & \\
\hline $\begin{array}{l}\text { Visualize each finger, hand, and arm as having } 4 \text { sides; wash all } 4 \text { sides effectively, keeping the } \\
\text { hand elevated; repeat the process for the opposite arm }\end{array}$ & $\mathrm{X}$ & \\
\hline Rinse hands and arms under running water in one direction from fingertips to elbows & $\mathrm{X}$ & \\
\hline Hold hands higher than elbows and away from surgical attire & $\mathrm{X}$ & $\mathrm{X}$ \\
\hline In the operating room, dry hands and arms with a sterile towel & $\mathrm{X}$ & \\
\hline
\end{tabular}

4. Inconclusive evidence has created confusion about appropriate hand hygiene during care of patients with CDI. Although in vivo studies show slight advantages for soap and water over ABHR, there are no clinical outcome studies suggesting the superiority of soap and water to ABHR for reducing CDI transmission; however, use of gloves has been associated with decreased CDI transmission, ${ }^{146}$ suggesting that appropriate use of gloves should be emphasized over hand hygiene methods when targeting prevention of CDI via contact transmission.

K. Hand preparation for surgery

1. ABHRs that are specially formulated for surgical use contain alcohol for rapid action against microorganisms and usually another antimicrobial for persistence. ${ }^{188}$ These products provide superior reductions in microorganisms compared with traditional hand scrubs, ${ }^{189-191}$ are less damaging to skin, ${ }^{190.192 .193}$ and are at least equivalent to surgical scrubs in preventing surgical site infections. ${ }^{192,194,195}$ Care must be taken to use surgical ABHR in accordance with manufacturers' instructions for surgical hand preparation. This requires multiple applications and a longer rub time than that for routine hand hygiene. Education should stress these differences because the products look fairly similar to ABHR for routine use. Failure to use the product properly may result in increased surgical site infection rates. ${ }^{196}$ Some members of the surgical team consider the hand scrub a ritual that is necessary to their preparations, in which case chlorhexidinecontaining scrubs have better efficacy in reducing colonization of the hands after 3 hours, although there is no evidence with respect to superiority in pre- venting surgical site infection. . $^{189-191,197}$ Traditional hand scrubs require the availability of clean water. In areas where clean water is not readily available, alcohol hand preparations are preferable.

2. The Association of periOperative Registered Nurses (AORN) recommends general procedures for traditional surgical scrub and application of surgical ABHR in the 2013 edition of "Recommended Practices for Hand Hygiene in the Perioperative Setting"198 (see Table 3).

L. Artificial nails and nail length

1. Outbreaks of HAIs have been attributed to artificial fingernails worn by HCP as well as long nail length. ${ }^{199,200}$

2. $\mathrm{CDC}$ and WHO guidelines recommend keeping nails to less than a quarter inch $(6.35 \mathrm{~mm})$ in length, although this recommendation was assigned a low evidence grade because it was based on an outbreak study where nail length was categorized subjectively. In a 2008 study by Rupp et al, ${ }^{185}$ investigators found that fingernail length greater than $2 \mathrm{~mm}$ was associated with increased microbial carriage on hands, suggesting that transmission is less likely with shorter nails.

3. Gloves more frequently puncture at the fingertip areas for the thumb and forefinger, reinforcing the relationship between nail length and glove puncture. ${ }^{148}$

4. To date, no evidence-based guidance on shellac (gel) nails or nail art exists. Policies regarding nail enhancements hinge on whether they are considered artificial nails or polish. A conservative approach treats them as artificial nails, in which case they should not be allowed on HCP treating high-risk patients. $^{1}$ 
TABLE 4. Grading of the Quality of Evidence

Grade
I. High
Highly confident that the true effect lies close to that of the estimated size and direction of the
effect. Evidence is rated as high quality when there is a wide range of studies with no major
limitations, there is little variation between studies, and the summary estimate has a narrow
confidence interval.
The true effect is likely to be close to the estimated size and direction of the effect, but there is
a possibility that it is substantially different. Evidence is rated as moderate quality when there
are only a few studies and some have limitations but not major flaws, there is some variation
between studies, or the confidence interval of the summary estimate is wide.
The true effect may be substantially different from the estimated size and direction of the effect.
Evidence is rated as low quality when supporting studies have major flaws, there is important
variation between studies, the confidence interval of the summary estimate is very wide, or
there are no rigorous studies, only expert consensus.

NoтE. Based on Grades of Recommendation, Assessment, Development, and Evaluation (GRADE) ${ }^{257}$ and the Canadian Task Force on Preventive Health Care. ${ }^{258}$

\section{SECTION 4: RECOMMENDED HAND}

\section{HYGIENE IMPROVEMENT STRATEGIES}

Recommendations are categorized as either (1) basic practices that should be adopted by all acute care hospitals or (2) special approaches that can be considered for use under specific circumstances (eg, outbreaks) when HAIs are not controlled by use of basic practices. Each infection prevention recommendation is given a quality-of-evidence ranking based on the Grades of Recommendation, Assessment, Development, and Evaluation (GRADE) system and the Canadian Task Force on Preventive Health Care (I, II, or III as defined in Table 4). None of the hand hygiene recommendations listed below achieve a category I ranking, which requires a wide range of studies demonstrating a similar size and direction of effect with narrow confidence intervals. CDC and WHO IA ("strongly recommended" and "strongly supported") hand hygiene recommendations are less specific than the GRADE system with regard to size and direction of effect and confidence intervals. The lack of randomized trials to test recommendations for hand hygiene indications that have become standard of care is likely to persist, largely due to ethical concerns. However, more rigorous studies could provide a better evidence base for other important aspects of hand hygiene, such as optimizing methods for hand hygiene measurement. Similarly, more rigorous multisite studies of implementation of hand hygiene programs and studies of hand hygiene in non-acute care settings are needed. Finally, establishing consistent methods for assessing the efficacy of various products relative to the volume and technique used in clinical settings is critical.

I. Basic practices for hand hygiene: recommended for all acute care hospitals

1. Select appropriate products (quality of evidence: II).

a. For routine hand hygiene, choose an ABHR with at least $62 \%$ alcohol.

b. Antimicrobial or nonantimicrobial soap should be available and accessible for routine hand hygiene in all patient care areas.

c. For surgical antisepsis, use an ABHR that is specially formulated for surgical use, containing alcohol for rapid action against microorganisms and another antimicrobial for persistence, ${ }^{188-191}$ or use an antimicrobial soap and water. Scrub brushes should be avoided because they damage skin. ${ }^{201,202}$

2. Provide convenient access to hand hygiene equipment and products by placing them strategically and assuring that they are refilled routinely as often as required (quality of evidence: III).

a. Sinks should be located conveniently and in accordance with the local applicable guidelines. ${ }^{203}$

b. Dispenser location may be determined by assessing staff workflow patterns or use of a more formal framework, such as Toyota Production Systems shop floor management. ${ }^{204}$ Counters in product dispensers can show which dispensers are frequently used and which are rarely used.

$i$. It is important to place hand hygiene products in the flow of work to promote adherence.

ii. Location of dispensers and storage of ABHR should be in compliance with fire codes.

3. Involve $\mathrm{HCP}$ in choosing products (quality of evidence: III).

a. Various components of hand hygiene products can cause irritation, ${ }^{205}$ and products that are not well accepted by $\mathrm{HCP}$ can negatively impact hand hygiene adherence.

4. Perform hand hygiene with an ABHR or, alternatively, an antimicrobial or nonantimicrobial soap for the following indications (quality of evidence: II).

a. Before direct patient contact. ${ }^{6,149,206,207}$

b. Before preparing or handling medication in anticipation of patient care (eg, in medication room or at medication cart before patient encounter). ${ }^{208,209}$ 
c. Before inserting an invasive device. ${ }^{210,211}$

d. Before and after handling an invasive device, including before accessing intravenous devices for medication administration. ${ }^{210,211}$

e. Before moving from a contaminated body site to a clean body site on the same patient. ${ }^{149,150,212}$

f. After direct patient contact. ${ }^{6,149,150,206}$

g. After removing gloves. ${ }^{147-149}$

h. After contact with blood or bodily fluids. ${ }^{213,214}$

i. After contact with the patient environment. ${ }^{150,206,215,216}$

5. Perform hand hygiene with antimicrobial or nonantimicrobial soap when hands are visibly soiled (quality of evidence: II). ${ }^{207,213,214,217}$

6. Assess unit- or institution-specific barriers to hand hygiene with frontline HCP for the purpose of identifying interventions that will be locally relevant (quality of evidence: III). ${ }^{15}$

7. Implement a multimodal strategy (or "bundle") for improving hand hygiene adherence to directly address the organization's most significant barriers (quality of evidence: II).

a. Use a bundled approach including enhanced access to $A B H R$, education, reminders, feedback, and administrative support. This combination of interventions had a significant collective impact on hand hygiene adherence. ${ }^{22}$

b. At a minimum, use a bundled approach including education, reminders, and feedback. ${ }^{22}$

8. Educate, motivate, and ensure competency of HCP (anyone caring for the patient on the institution's behalf) about proper hand hygiene (quality of evidence: III).

a. Educate HCP through regular sessions at hire, when job functions change, and at least annually.

$i$. When possible, use interactive means, such as fluorescing indicators, to simulate hand contamination and subsequent removal and visual reminders, such as culture plates of hands or audience response systems, to keep the audience engaged.

b. Ensure competency of HCP by testing knowledge of the indications for hand hygiene and requiring demonstration of appropriate hand hygiene technique. ${ }^{218,219}$

c. Educate patients and families about hand hygiene on admission to healthcare facilities and when changes in circumstances warrant. Encourage patients and families to remind HCP to clean their hands before care episodes. $^{220}$

d. Motivate HCP to perform hand hygiene using positive message framing for hand hygiene messaging and posters. ${ }^{21}$

e. Use behavioral frameworks and recognized behavioral techniques to plan and execute interventions. ${ }^{222}$

9. Measure hand hygiene adherence via direct observation (human observers), product volume measurement, or automated monitoring (quality of evidence: II).

a. Decide on the type of measurement system on the basis of resource availability and commitment to using the data collected productively. Consider the advantages and limitations of each type of monitoring.

$i$. Use direct observation to elucidate contextual barriers and facilitators to hand hygiene and to provide corrective feedback to individuals.

ii. Use product volume measurement for large-scale benchmarking but complement with direct observation when possible.

iii. Use automated systems to provide real-time reminders and generate feedback for quality improvement. Be aware that such systems have been mainly used in research settings. They may be limited in their capacity to accurately measure opportunities within each patient care encounter; these systems can, however, measure a large sample of hand hygiene opportunities and can be useful for measuring trends over time and generating real-time displays for feedback.

10. Provide feedback to HCP on hand hygiene performance (quality of evidence: III).

a. Provide feedback in multiple formats and on more than one occasion. ${ }^{223}$

b. Provide meaningful data with clear targets and an action plan in place for improving adherence. ${ }^{223}$

$i$. Meaningful data may include unit- or role-based adherence data rather than overall performance. ${ }^{17}$

ii. Real-time displays of hand hygiene adherence may provide some incentive for improvement on a shift-by-shift basis.

II. Special approaches for hand hygiene practices

1. During norovirus outbreaks, in addition to contact precautions requiring the use of gloves, consider preferential use of soap and water after caring for patients with known or suspected norovirus infection (quality of evidence: III).

2. During $C$. difficile outbreaks or in settings with hyperendemic CDI, in addition to contact precautions requiring the use of gloves, consider preferential use of soap and water after caring for patients with known or suspected CDI (quality of evidence: III).

III. Approaches that should not be considered part of routine hand hygiene

1. Do not use hot water for hand washing because it can irritate the skin.

2. Do not use ABHR when hands are visibly soiled.

3. Do not use triclosan-containing soaps. There is a lack of evidence to support the equivalent or superior effectiveness (ie, better clinical outcomes) of triclosan compared with chlorhexidine gluconate soaps or ABHR. ${ }^{156,157,163,187}$ Given concerns about the potential human and environmental impacts of this chemical ${ }^{169-172}$ combined with its potential to promote resistance, ${ }^{164,165}$ triclosan-containing soaps should be avoided until the benefits versus risks can be adequately characterized. ${ }^{158}$ 
4. Do not use self-report as the primary method of hand hygiene adherence measurement. ${ }^{17}$

IV. Unresolved issues

1. Whether to prohibit or allow shellac (gel) nails and nail enhancements on HCP is unresolved. If institutions consider these nail adherents artificial, then they should be prohibited among HCP caring for high-risk patients per existing CDC and WHO guidance. Whether shellac (gel) nails are "artificial," however, is controversial.

2. More research is needed to assess whether donning nonsterile gloves without prior hand hygiene is safe for patient care and whether it leads to significant increases in contamination of unused gloves in glove boxes. Additionally, engineering solutions that could reduce potential contamination of unused gloves during removal from the box should be pursued.

3. Policies requiring hand washing or scrubbing on entry to high-risk areas, such as neonatal intensive care units or burn units, are common, but there are no data to support or refute these practices. Hand hygiene before patient contact in these settings is recommended, but it is unclear whether additional benefit is conferred by washing or scrubbing on entry and before reaching the patient care area.

4. Although many manufacturers of surgical hand preparation products stipulate use of picks and brushes, 2 recent studies showed no benefit to the use of picks or brushes. ${ }^{201,202}$

5. There is no national standard for measuring hand hygiene adherence. This includes the optimal number of observations, which indications should be monitored, whether technique should be considered, and the best method to assess adherence.

\section{SECTION 5: PERFORMANCE MEASURES}

I. Internal reporting

A. Hand hygiene adherence measurement is not standardized in the United States, and measurement of hand hygiene adherence will depend on the resources available to a given institution at a given time. These measures are intended to support internal quality improvement through measurement, feedback, and longitudinal assessment of interventions at individual facilities or clusters of facilities in the same health system.

1. Direct observation: a human observer audits a healthcare area (either in person or by video monitoring) and observes whether HCP perform hand hygiene for a prespecified set of indications, including the following:

a. On entry, exit, and various points in patient care (as defined by the CDC, the WHO's 5 Moments for Hand Hygiene, or other initiatives, such as the Canadian 4 Moments for Hand Hygiene or internal surveys). b. On healthcare worker entry and exit to patient rooms.

c. Numerator: number of successful hand hygiene actions performed, meaning that a healthcare worker performs hand hygiene for the prespecified set of indications observed (eg, 5 moments versus in-out; Figure 1).

d. Denominator: number of hand hygiene opportunities observed, defined by the prespecified set of indications observed.

e. Hand hygiene adherence metric: (successful hand hygiene actions)/(opportunities observed) $\times 100 \%$.

2. Product volume measurement

a. Numerator: milliliters of hand hygiene product used (eg, ABHR or liquid soap) for a specified period of time in a specified area.

b. Denominator: 1,000 patient-days during specified period in specified area ${ }^{37,54}$ or number of patient visits for out-patient areas or emergency departments. $^{55}$

c. Product usage metric: milliliters per 1,000 patientdays or per patient visit.

3. Automated monitoring

a. Electronic counting: number of dispensing episodes per patient-day.

b. Radiofrequency identification, wireless, ultrasound, or infrared sensing:

c. Numerator: number of approximated hand hygiene actions detected by sensors.

d. Denominator: number of approximated hand hygiene opportunities detected by sensors.

e. Metric for approximate hand hygiene adherence: (hand hygiene actions approximated)/(hand hygiene opportunities approximated) $\times 100 \%$.

II. External reporting

Unlike various HAIs measured with standardized case definitions and reported through the National Healthcare Safety Network, there is no standardized metric for hand hygiene adherence reporting. Because the credibility of various methods has yet to be established, any publicly reported hand hygiene metric will suffer from distrust of the data due to misaligned incentives. ${ }^{224}$

\section{SECTION 6: EXAMPLES OF}

\section{IMPLEMENTATION STRATEGIES}

Accountability is an essential principle for preventing HAIs. It provides the necessary translational link between science and implementation. Without clear accountability, scientifically based implementation strategies will be used in an inconsistent and fragmented way, decreasing their effectiveness in preventing HAIs. Accountability begins with the chief executive officer and other senior leaders who provide the imperative for HAI prevention, thereby making HAI prevention an organizational priority. Senior leadership is accountable 
TABLE 5. Fundamental Elements of Accountability for Healthcare-Associated Infection Prevention

Senior management is responsible for ensuring that the healthcare system supports an infection prevention and control (IPC) program that effectively prevents healthcare-associated infections (HAIs) and the transmission of epidemiologically important pathogens

Senior management is accountable for ensuring that an adequate number of trained personnel are assigned to the IPC program and adequate staffing of other departments that play a key role in HAI prevention (eg, environmental services)

Senior management is accountable for ensuring that healthcare personnel, including licensed and nonlicensed personnel, are adequately trained and competent to perform their job responsibilities

Direct healthcare providers (such as physicians, nurses, aides, and therapists) and ancillary personnel (such as environmental service and equipment processing personnel) are responsible for ensuring that appropriate IPC practices are used at all times (including hand hygiene, standard and isolation precautions, and cleaning and disinfection of equipment and the environment)

Senior and unit leaders are responsible for holding personnel accountable for their actions, including development of progressive discipline for habitual nonadherence to HAI prevention strategies

IPC leadership is responsible for ensuring that an active program to identify HAIs is implemented, that HAI data are analyzed and regularly provided to those who can use the information to improve the quality of care (eg, unit staff, clinicians, and hospital administrators), and that evidence-based practices are incorporated into the program

Senior and unit leaders are accountable for ensuring that appropriate training and educational programs to prevent HAIs are developed and provided to personnel, patients, and families

Personnel from the IPC program, the laboratory, and information technology departments are responsible for ensuring that systems are in place to support the surveillance program

for providing adequate resources needed for effective implementation of an HAI prevention program. These resources include necessary personnel (clinical and nonclinical), education, and equipment as well as structure for escalating situations of continued nonadherence (Table 5).

Strategies for implementation of multimodal hand hygiene improvement programs-including system/infrastructure change (eg, availability of $A B H R s$ ), education, evaluation and feedback, reminders (eg, posters), and institutional safety climate (eg, administrative support)-have been endorsed and detailed by the WHO in a 2009 publication titled A Guide to the Implementation of the WHO Multimodal Hand Hygiene Improvement Strategy (http://whqlibdoc.who.int/hq/2009 /WHO_IER_PSP_2009.02_eng.pdf). ${ }^{14}$ While the United States does not have a national campaign with universal emphasis on the WHO's improvement program, as 48 other countries do, many hospitals in the United States had existing hand hygiene programs at the time when the WHO's implementation guide was published that incorporated various combinations of the WHO's recommended strategies. Other strategic guides to implementation of hand hygiene improvement programs used in US hospitals include the Institute for Healthcare Improvement's how-to guide, available for free (http://www.ihi.org /knowledge/Pages/Tools/HowtoGuideImprovingHandHygiene .aspx), and The Joint Commission Center for Transforming Healthcare's targeted solutions tool (TST) for hand hygiene. The TST is available to Joint Commission-accredited organizations at no charge and is available for a fee to organizations that are not accredited by The Joint Commission (http:// www.centerfortransforminghealthcare.org/tst_hh.aspx).

In general, studies examining the association between hand hygiene improvement programs and increases in hand hygiene adherence (and/or decreases in HAIs) do not meet quality standards required of meta-analytic reviews. A Cochrane review published in 2010 found that only 4 studies of the impact of hand hygiene improvement programs were of sufficient rigor to include in the review. ${ }^{21}$ A 2014 meta-analysis by Schweizer et $\mathrm{al}^{22}$ used relaxed inclusion criteria and reviewed 45 studies. The impact of each bundle element individually could not be evaluated because implementation occurred in parallel with other elements, hindering the ability to disentangle the impact of any single element. The section below references studies that describe and evaluate hand hygiene improvement interventions, presenting them in terms of improvement interventions and describing basic intervention elements.

\section{Engage}

A. Develop a multidisciplinary team that includes representatives from administrative leadership ${ }^{60,68,25-227}$ as well as local (unit-level) champions..$^{65,68,228,229}$

1. Define the barriers to hand hygiene that are specific to the unit or institution. ${ }^{15}$

2. Ensure that institutional leadership is aware and supportive of hand hygiene improvement strategies and supports these efforts with adequate resources. Leadership engagement is critical to success.

B. Utilize peer networking to encourage persistent salience of hand hygiene.

1. Consider rewards or recognition for wards modeling good hand hygiene behaviors or improvement. ${ }^{60,227,230}$

2. Qualitative studies suggest that role modeling, particularly that of physicians, is important yet underappreciated. ${ }^{222,231}$

3. Encourage patients to take an active role in reminding doctors to perform hand hygiene. ${ }^{220,232-234}$ A patient advocacy video is available on the CDC's website (http://www.cdc.gov/handhygiene/Patient_materials .html). 
II. Educate

A. Educate providers on recommended indications and techniques for hand hygiene. Use educational tools that clearly define hand hygiene indications and teach the logic behind each one (eg, 5 Moments for Hand Hygiene).

B. Consider the use of interactive methods, such as UV light boxes. $229,235,236$

C. Consider targeting education to specific groups or facility-specific knowledge gaps or misconceptions (eg, as determined by surveys). ${ }^{237,238}$

D. Assess competency regarding hand hygiene with tests of didactic knowledge and demonstration of proper hand hygiene techniques. ${ }^{218,219}$

III. Execute

A. Provide access to ABHR. In the early 2000 s, studies in North America and Europe demonstrated that introduction of $A B H R$ was associated with increased hand hygiene adherence and decreased HAIs. ${ }^{68,225,239,240}$ Where ABHR has been introduced more recently (eg, in developing countries), similar results have been demonstrated..$^{241-243}$

B. Implement a multimodal (ie, bundled) hand hygiene improvement program. A 2014 meta-analysis evaluated several bundle combinations and found that hand hygiene improvement bundles that included enhanced access to ABHR, education, reminders, feedback, and administrative support had a significant collective impact on hand hygiene adherence; ${ }^{22}$ of note, these are the same key elements included in the WHO's implementation guide, also referred to as the "Geneva bundle." Pooled findings from studies of bundles including education, reminders, and feedback also showed a significant, but less pronounced, impact on hand hygiene adherence. ${ }^{22}$ Recognize that interventions must be ongoing to maintain behavior change and improved adherence. ${ }^{68}$

C. Identify barriers to hand hygiene specific to the unit or institution. Some institutions have used Lean Six Sigma and root-cause analysis to elucidate the most relevant causes of hand hygiene failure in their setting. This information is then used to create interventions specific to their needs.

D. Focus on targeted behavior change. Posters should be motivational in nature rather than simply conveying information; emphasis on personal responsibility and altruism are important. ${ }^{221,244}$

IV. Evaluate

A. Measure hand hygiene adherence performance. A combination of approaches may be most appropriate (see section II).

B. Measurement may need to be adjusted for facility-specific needs. Use or build on existing tools.

1. WHO observation forms available for free can be found at http://www.who.int/entity/gpsc/5may /Observation_Form.doc. ${ }^{27}$
2. A variety of other forms are available for free in The Joint Commission's hand hygiene monograph at http://www.jointcommission.org/topics/hai_hand _hygiene.aspx. ${ }^{17}$

3. The Joint Commission Center for Transforming Healthcare's targeted solutions tool for hand hygiene (http://www.centerfortransforminghealthcare.org/tst _hh.aspx) is available for free to organizations accredited by The Joint Commission. ${ }^{15}$

4. The iScrub application to assist with direct observation is available for free at http://compepi.cs .uiowa.edu/index.php/Research/IScrub.

C. Provide meaningful feedback on hand hygiene performance with clear targets and an action plan in place for improving adherence. ${ }^{223,245}$

1. Feedback of hand hygiene adherence rates has long been recognized as an important component of multimodal hand hygiene improvement programs, ${ }^{55,57,68,246,247}$ although the independent impact of feedback apart from other bundled hand hygiene interventions is not known. ${ }^{22}$

2. Feedback may be most effective when provided more than once, when both verbal and written feedback are provided, and when a superior or colleague is responsible for the audit and feedback. ${ }^{245}$

3. Providing overall hand hygiene adherence rates for a facility may not be as effective as unit-based or rolebased reports at identifying problem areas and planning focused training efforts. ${ }^{248}$

4. Hand hygiene data may be displayed on dashboards that provide the most recent or cumulative hand hygiene adherence rates compared with a target rate ${ }^{249}$ or statistical process control charts that show data trends over time and whether changes in rates are due to specific interventions or normal variation. ${ }^{250}$ Some automated monitoring systems have the ability to give real-time displays of unit hand hygiene adherence, providing some incentive for improvement on a shift-by-shift basis.

5. Use feedback to engage HCP in identifying problems at the individual hospital or unit level, and use data to tailor ongoing interventions.

6. If individually identified hand hygiene adherence rates are used, consider providing feedback privately versus in a public staff setting. ${ }^{248}$

7. Some facilities report hand hygiene adherence data in conjunction with hospital-associated infection rates. ${ }^{730,251}$ Although an association between hand hygiene and $\mathrm{HAI}$ reductions has been reported in the literature, the association may not be evident in individual unit or facility data because of confounding factors (eg, environmental cleanliness and small sample sizes). ${ }^{25,43,184,252-254}$ 


\section{ACKNOWLEDGMENTS}

We thank Kaleigh Beronja, Danielle Moulia, Sandhya Kajeepta, Jonathan Silverberg, and Kara Tarter for their assistance in assembling and reviewing hand hygiene literature.

Disclaimer. K.E.-The findings and conclusions in this report are those of the authors and do not necessarily represent the official position of the Centers for Disease Control and Prevention.

Potential conflicts of interest. J.P.H. reports receiving research grant/contract support from 3M. A.E.A. reports serving as an advisor/consultant for the Tork Green Hygiene Council of SCA Tork and Grant \& Eisenhofer. L.K. reports being an employee of The Joint Commission and receiving grant/ contract support from Sanofi Pasteur and Baxter Healthcare. R.N.O. reports serving on the speakers' bureau for Ethicon and Avid Education Partners and serving as an advisor/consultant for Premier. E.P. reports serving as an advisor/consultant for Pur Thread. P.M.P. reports receiving grant/contract support from GOJO industries in the form of a gift to the University of Iowa Foundation. K.E., L.L.M., M.L.S., P.T., M.V.A., and D.S.Y. report no relevant conflicts of interest.

Address correspondence to Janet P. Haas, PhD, RN, CIC, Westchester Medical Center Infection Prevention and Control, Macy Pavilion SW-246, 100 Woods Road, Valhalla, NY 10595 (haasj@wcmc.com).

\section{REFERENCES}

1. Boyce JM, Pittet D. Guideline for hand hygiene in health-care settings: recommendations of the Healthcare Infection Control Practices Advisory Committee and the HIPAC/SHEA/APIC/ IDSA Hand Hygiene Task Force. Am I Infect Control 2002;30: S1-S46.

2. Pittet D, Allegranzi B, Boyce J. The World Health Organization Guidelines on Hand Hygiene in Health Care and their consensus recommendations. Infect Control Hosp Epidemiol 2009; 30:611-622.

3. Yokoe DS, Anderson DJ, Berenholtz SM, et al. Introduction to "A Compendium of Strategies to Prevent Healthcare-Associated Infections in Acute Care Hospitals: 2014 Updates." Infect Control Hosp Epidemiol 2014;35:455-459.

4. Lane HJ, Blum N, Fee E. Oliver Wendell Holmes (1809-1894) and Ignaz Philipp Semmelweis (1818-1865): preventing the transmission of puerperal fever. Am J Public Health 2010;100: 1008-1009.

5. Gould IM. Alexander Gordon, puerperal sepsis, and modern theories of infection control-Semmelweis in perspective. Lancet Infect Dis 2010;10:275-278.

6. Mortimer EA Jr, Lipsitz PJ, Wolinsky E, Gonzaga AJ, Rammelkamp CH Jr. Transmission of staphylococci between newborns: importance of the hands to personnel. Am J Dis Child 1962;104:289-295.

7. Allegranzi B, Pittet D. Role of hand hygiene in healthcareassociated infection prevention. J Hosp Infect 2009;73:305-315.

8. Mody L, Saint S, Kaufman SR, Kowalski C, Krein SL. Adoption of alcohol-based handrub by United States hospitals: a national survey. Infect Control Hosp Epidemiol 2008;29:1177-1180.

9. Voss A, Widmer AF. No time for handwashing!? handwashing versus alcoholic rub: can we afford $100 \%$ compliance? Infect Control Hosp Epidemiol 1997;18:205-208.

10. Kownatzki E. Hand hygiene and skin health. J Hosp Infect 2003; 55:239-245.

11. Erasmus V, Daha TJ, Brug $\mathrm{H}$, et al. Systematic review of studies on compliance with hand hygiene guidelines in hospital care. Infect Control Hosp Epidemiol 2010;31:283-294.

12. Harris AD, Samore MH, Nafziger R, DiRosario K, Roghmann $\mathrm{MC}$, Carmeli Y. A survey on handwashing practices and opinions of healthcare workers. J Hosp Infect 2000;45:318-321.

13. Lankford MG, Zembower TR, Trick WE, Hacek DM, Noskin GA, Peterson LR. Influence of role models and hospital design on hand hygiene of healthcare workers. Emerg Infect Dis 2003; 9:217-223.

14. World Health Organization (WHO). A Guide to the Implementation of the WHO Multimodal Hand Hygiene Improvement Strategy. Geneva: WHO, 2009.

15. The Joint Commission Center for Transforming Healthcare. Targeted Solutions Tool for Hand Hygiene. http://www .centerfortransforminghealthcare.org/tst_hh.aspx. Accessed December 27, 2013.

16. Allegranzi B, Conway L, Larson E, Pittet D. Status of the implementation of the World Health Organization multimodal hand hygiene strategy in United States of America health care facilities. Am J Infect Control 2014;42:224-230.

17. The Joint Commission. Measuring Hand Hygiene Adherence: Overcoming the Challenges. http://www.jointcommission.org /assets/1/18/hh_monograph.pdf. Published 2009. Accessed May 18, 2013.

18. World Health Organization. SAVE LIVES: Clean Your Hands, Tools and Resources for Evaluation and Feedback. http://www .who.int/gpsc/5may/tools/evaluation_feedback/en/. Accessed May 18, 2013.

19. McGuckin M, Govednik J. Hand hygiene product volume measurement: an integral part of a multiple-method program. Infect Control Hosp Epidemiol. 2010;31:980-981.

20. Boyce JM. Hand hygiene compliance monitoring: current perspectives from the USA. J Hosp Infect 2008;70(suppl 1):2-7.

21. Gould DJ, Moralejo D, Drey N, Chudleigh JH. Interventions to improve hand hygiene compliance in patient care. Cochrane Database Syst Rev 2010:CD005186.

22. Schweizer ML, Reisinger HS, Ohl M, et al. Searching for an optimal hand hygiene bundle: a meta-analysis. Clin Infect Dis 2014;58:248-259.

23. Talbot TR, Johnson JG, Fergus C, et al. Sustained improvement in hand hygiene adherence: utilizing shared accountability and financial incentives. Infect Control Hosp Epidemiol 2013;34: 1129-1136.

24. Eveillard M, Hitoto $H$, Raymond $F$, et al. Measurement and interpretation of hand hygiene compliance rates: importance of monitoring entire care episodes. J Hosp Infect 2009;72:211217.

25. Haas JP, Larson EL. Measurement of compliance with hand hygiene. J Hosp Infect 2007;66:6-14.

26. Sax H, Allegranzi B, Uckay I, Larson E, Boyce J, Pittet D. "My Five Moments for Hand Hygiene": a user-centred design approach to understand, train, monitor and report hand hygiene. J Hosp Infect 2007;67:9-21.

27. Sax H, Allegranzi B, Chraiti MN, Boyce J, Larson E, Pittet D. The World Health Organization hand hygiene observation method. Am J Infect Control 2009;37:827-834.

28. Stewardson A, Sax H, Longet-Di Pietro S, Pittet D. Impact of observation and analysis methodology when reporting hand hygiene data. J Hosp Infect 2011;77:358-359.

29. Marra AR, Camargo TZ, Cardoso VI, et al. Hand hygiene 
compliance in the critical care setting: a comparative study of 2 different alcohol handrub formulations. Am J Infect Control 2013;41:136-139.

30. Canada's Hand Hygiene Challenge. Hand Hygiene Toolkit. Your 4 Moments for Hand Hygiene [poster]. http:// www. handhygiene.ca/English/Documents / Tools\%20and $\% 20$ Templates/Your $\% 204 \% 20$ Moments $\% 20$ for $\% 20 \mathrm{Hand}$ $\% 20$ Hygiene $\% 20 \% 28$ Poster\%29.pdf. Accessed April 3, 2014.

31. Centers for Disease Control and Prevention, National Healthcare Safety Network. Multidrug-Resistant Organism and Clostridium difficile Infection (MDRO/CDI) Module. http://www .cdc.gov/nhsn/PDFs/pscManual/12pscMDRO_CDADcurrent .pdf. Accessed April 2, 2014.

32. Reisinger HS, Yin J, Radonovich L, et al. Comprehensive survey of hand hygiene measurement and improvement practices in the Veterans Health Administration. Am J Infect Control 2013; 41:989-993.

33. Al-Tawfiq JA, Abed MS, Al-Yami N, Birrer RB. Promoting and sustaining a hospital-wide, multifaceted hand hygiene program resulted in significant reduction in health care-associated infections. Am J Infect Control 2013;41:482-486.

34. Gould DJ, Chudleigh J, Drey NS, Moralejo D. Measuring handwashing performance in health service audits and research studies. J Hosp Infect 2007;66:109-115.

35. Gould DJ, Drey NS, Creedon S. Routine hand hygiene audit by direct observation: has nemesis arrived? J Hosp Infect 2011; 77:290-293.

36. van de Mortel T, Murgo M. An examination of covert observation and solution audit as tools to measure the success of hand hygiene interventions. Am I Infect Control 2006;34:9599.

37. Boyce JM. Measuring healthcare worker hand hygiene activity: current practices and emerging technologies. Infect Control Hosp Epidemiol 2011;32:1016-1028.

38. Kohli E, Ptak J, Smith R, Taylor E, Talbot EA, Kirkland KB. Variability in the Hawthorne effect with regard to hand hygiene performance in high- and low-performing inpatient care units. Infect Control Hosp Epidemiol 2009;30:222-225.

39. Dhar S, Tansek R, Toftey EA, et al. Observer bias in hand hygiene compliance reporting. Infect Control Hosp Epidemiol 2010;31:869-870.

40. Pan SC, Tien KL, Hung IC, et al. Compliance of health care workers with hand hygiene practices: independent advantages of overt and covert observers. PloS ONE 2013;8:e53746.

41. Larson EL, Aiello AE, Cimiotti JP. Assessing nurses' hand hygiene practices by direct observation or self-report. J Nurs Meas 2004;12:77-85.

42. Kowitt B, Jefferson J, Mermel LA. Factors associated with hand hygiene compliance at a tertiary care teaching hospital. Infect Control Hosp Epidemiol 2013;34:1146-1152.

43. Fries J, Segre AM, Thomas G, Herman T, Ellingson K, Polgreen PM. Monitoring hand hygiene via human observers: how should we be sampling? Infect Control Hosp Epidemiol 2012; 33:689-695.

44. Sharma D, Thomas GW, Foster ED, et al. The precision of human-generated hand-hygiene observations: a comparison of human observation with an automated monitoring system. Infect Control Hosp Epidemiol 2012;33:1259-1261.

45. Hlady CS, Severson MA, Segre AM, Polgreen PM. A mobile handheld computing application for recording hand hygiene observations. Infect Control Hosp Epidemiol 2010;31:975-977.

46. Chen LF, Carriker C, Staheli R, et al. Observing and improving hand hygiene compliance: implementation and refinement of an electronic-assisted direct-observer hand hygiene audit program. Infect Control Hosp Epidemiol 2013;34:207-210.

47. Erasmus V, Kuperus MN, Richardus JH, Vos MC, Oenema A, van Beeck EF. Improving hand hygiene behaviour of nurses using action planning: a pilot study in the intensive care unit and surgical ward. $J$ Hosp Infect 2010;76:161-164.

48. Graf K, Ott E, Wolny M, et al. Hand hygiene compliance in transplant and other special patient groups: an observational study. Am J Infect Control 2013;41:503-508.

49. Davis CR. Infection-free surgery: how to improve handhygiene compliance and eradicate methicillin-resistant Staphylococcus aureus from surgical wards. Ann $R$ Coll Surg Engl 2010;92:316-319.

50. Armellino D, Trivedi M, Law I, et al. Replicating changes in hand hygiene in a surgical intensive care unit with remote video auditing and feedback. Am J Infect Control 2013;41:925-927.

51. Armellino D, Hussain E, Schilling ME, et al. Using high-technology to enforce low-technology safety measures: the use of third-party remote video auditing and real-time feedback in healthcare. Clin Infect Dis 2012;54:1-7.

52. Palmore TN, Henderson DK. Big brother is washing ... video surveillance for hand hygiene adherence, through the lenses of efficacy and privacy. Clin Infect Dis 2012;54:8-9.

53. Behnke M, Gastmeier P, Geffers C, Monch N, Reichardt C. Establishment of a national surveillance system for alcoholbased hand rub consumption and change in consumption over 4 years. Infect Control Hosp Epidemiol 2012;33:618-620.

54. Marra AR, Moura DF Jr, Paes AT, dos Santos OF, Edmond MB. Measuring rates of hand hygiene adherence in the intensive care setting: a comparative study of direct observation, product usage, and electronic counting devices. Infect Control Hosp Epidemiol 2010;31:796-801.

55. McGuckin M, Waterman R, Govednik J. Hand hygiene compliance rates in the United States-a one-year multicenter collaboration using product/volume usage measurement and feedback. Am J Med Qual 2009;24:205-213.

56. Scheithauer S, Oude-Aost J, Heimann K, et al. Hand hygiene in pediatric and neonatal intensive care unit patients: daily opportunities and indication- and profession-specific analyses of compliance. Am I Infect Control 2011;39:732-737.

57. Larson EL, Early E, Cloonan P, Sugrue S, Parides M. An organizational climate intervention associated with increased handwashing and decreased nosocomial infections. Behav Med $2000 ; 26: 14-22$.

58. Larson EL, Albrecht S, O'Keefe M. Hand hygiene behavior in a pediatric emergency department and a pediatric intensive care unit: comparison of use of 2 dispenser systems. Am J Crit Care 2005; 14:304-311.

59. Kinsella G, Thomas AN, Taylor RJ. Electronic surveillance of wall-mounted soap and alcohol gel dispensers in an intensive care unit. J Hosp Infect 2007;66:34-39.

60. Whitby M, McLaws ML, Slater K, Tong E, Johnson B. Three successful interventions in health care workers that improve compliance with hand hygiene: is sustained replication possible? Am J Infect Control 2008;36:349-355.

61. Koff MD, Corwin HL, Beach ML, Surgenor SD, Loftus RW. 
Reduction in ventilator associated pneumonia in a mixed intensive care unit after initiation of a novel hand hygiene program. J Crit Care 2011;26:489-495.

62. Helder OK, Weggelaar AM, Waarsenburg DC, et al. Computer screen saver hand hygiene information curbs a negative trend in hand hygiene behavior. Am J Infect Control 2012;40:951954.

63. Boyce JM, Cooper T, Dolan MJ. Evaluation of an electronic device for real-time measurement of alcohol-based hand rub use. Infect Control Hosp Epidemiol 2009;30:1090-1095.

64. Marra AR, D'Arco C, Bravim Bde A, et al. Controlled trial measuring the effect of a feedback intervention on hand hygiene compliance in a step-down unit. Infect Control Hosp Epidemiol 2008;29:730-735.

65. Marra AR, Guastelli LR, de Araujo CM, et al. Positive deviance: a program for sustained improvement in hand hygiene compliance. Am J Infect Control 2011;39:1-5.

66. Marra AR, Guastelli LR, de Araujo CM, et al. Positive deviance: a new strategy for improving hand hygiene compliance. Infect Control Hosp Epidemiol 2010;31:12-20.

67. Koff MD, Loftus RW, Burchman CC, et al. Reduction in intraoperative bacterial contamination of peripheral intravenous tubing through the use of a novel device. Anesthesiology 2009; 110:978-985.

68. Pittet D, Hugonnet $S$, Harbarth $S$, et al; Infection Control Programme. Effectiveness of a hospital-wide programme to improve compliance with hand hygiene. Lancet 2000; 356(9238):1307-1312.

69. Boyce JM, Ligi C, Kohan C, Dumigan D, Havill NL. Lack of association between the increased incidence of Clostridium difficile-associated disease and the increasing use of alcoholbased hand rubs. Infect Control Hosp Epidemiol 2006;27:479483.

70. Eldridge NE, Woods SS, Bonello RS, et al. Using the Six Sigma process to implement the Centers for Disease Control and Prevention Guideline for Hand Hygiene in 4 intensive care units. J Gen Intern Med 2006;21 (suppl 2):S35-S42.

71. Magiorakos AP, Leens E, Drouvot V, et al. Pathways to clean hands: highlights of successful hand hygiene implementation strategies in Europe. Euro Surveill 2010;15:19560.

72. Muller A, Denizot V, Mouillet S, et al. Lack of correlation between consumption of alcohol-based solutions and adherence to guidelines for hand hygiene. J Hosp Infect 2005;59:163164.

73. Morgan DJ, Pineles L, Shardell M, et al. Automated hand hygiene count devices may better measure compliance than human observation. Am J Infect Control 2012;40:955-959.

74. Boscart VM, Gorski S, Holliday PJ, et al. Advanced technologies to curb healthcare-associated infections. Healthc Pap 2009;9: 51-55.

75. Ferenc J. Handy solutions: hygiene compliance monitoring goes high-tech. Health Facil Manage 2012;25:32-36.

76. Swoboda SM, Earsing K, Strauss K, Lane S, Lipsett PA. Electronic monitoring and voice prompts improve hand hygiene and decrease nosocomial infections in an intermediate care unit. Crit Care Med 2004;32:358-363.

77. Venkatesh AK, Lankford MG, Rooney DM, Blachford T, Watts $\mathrm{CM}$, Noskin GA. Use of electronic alerts to enhance hand hygiene compliance and decrease transmission of vancomycin- resistant Enterococcus in a hematology unit. Am J Infect Control 2008;36:199-205.

78. Swoboda SM, Earsing K, Strauss K, Lane S, Lipsett PA. Isolation status and voice prompts improve hand hygiene. Am I Infect Control 2007;35:470-476.

79. Fakhry MG, Hanna B, Anderson O, Holmes A, Nathwani D. Effectiveness of an audible reminder on hand hygiene adherence. Am I Infect Control 2012;40:320-323.

80. Cheng VC, Tai JW, Ho SK, et al. Introduction of an electronic monitoring system for monitoring compliance with moments 1 and 4 of the WHO "My 5 Moments for Hand Hygiene" methodology. BMC Infect Dis 2011;11:151.

81. Sahud AG, Bhanot N. Measuring hand hygiene compliance: a new frontier for improving hand hygiene. Infect Control Hosp Epidemiol 2009;30:1132.

82. Polgreen PM, Hlady CS, Severson MA, Segre AM, Herman T. Method for automated monitoring of hand hygiene adherence without radio-frequency identification. Infect Control Hosp Epidemiol 2010;31:1294-1297.

83. Edmond MB, Goodell A, Zuelzer W, Sanogo K, Elam K, Bearman G. Successful use of alcohol sensor technology to monitor and report hand hygiene compliance. J Hosp Infect 2010;76: 364-365.

84. Sahud AG, Bhanot N, Radhakrishnan A, Bajwa R, Manyam H, Post JC. An electronic hand hygiene surveillance device: a pilot study exploring surrogate markers for hand hygiene compliance. Infect Control Hosp Epidemiol 2010;31:634-639.

85. Pineles LL, Morgan DJ, Limper HM, et al. Accuracy of a radiofrequency identification (RFID) badge system to monitor hand hygiene behavior during routine clinical activities. $A m J$ Infect Control 2014;42:144-147.

86. Polgreen P. Badge brings automated edge to infection control. Mater Manag Health Care 2009:15-17.

87. Boscart VM, McGilton KS, Levchenko A, Hufton G, Holliday P, Fernie GR. Acceptability of a wearable hand hygiene device with monitoring capabilities. J Hosp Infect 2008;70:216-222.

88. Levchenko AI, Boscart M, Fernie GR. The feasibility of an automated monitoring system to improve nurses' hand hygiene. Int J Med Inform 2011;80:596-603.

89. Ellingson K, Polgreen PM, Schneider A, et al. Healthcare personnel perceptions of hand hygiene monitoring technology. Infect Control Hosp Epidemiol 2011;32:1091-1096.

90. Siegel JD, Rhinehart E, Jackson M, Chiarello L. 2007 Guideline for isolation precautions: preventing transmission of infectious agents in health care settings. Am J Infect Control 2007;35(10 suppl 2):S65-S164.

91. MacCannell T, Umscheid CA, Agarwal RK, Lee I, Kuntz G, Stevenson KB. Guideline for the prevention and control of norovirus gastroenteritis outbreaks in healthcare settings. Infect Control Hosp Epidemiol 2011;32:939-969.

92. Gould CV, Umscheid CA, Agarwal RK, Kuntz G, Pegues DA. Guideline for prevention of catheter-associated urinary tract infections 2009. Infect Control Hosp Epidemiol 2010;31:319326.

93. Mangram AJ, Horan TC, Pearson ML, Silver LC, Jarvis WR; Hospital Infection Control Practices Advisory Committee. Guideline for prevention of surgical site infection, 1999. Infect Control Hosp Epidemiol 1999;20:250-278.

94. O'Grady NP, Alexander M, Burns LA, et al. Guidelines for the 
prevention of intravascular catheter-related infections. Am J Infect Control 2011;39(4 suppl 1):S1-S34.

95. Ayliffe GA, Bridges K, Lilly HA, Lowbury EJ, Varney J, Wilkins $\mathrm{MD}$. Comparison of two methods for assessing the removal of total organisms and pathogens from the skin. J Hyg (Lond) 1975;75:259-274.

96. Blech MF, Hartemann P, Paquin JL. Activity of non antiseptic soaps and ethanol for hand disinfection. Zentralbl Bakteriol Mikrobiol Hyg B 1985;181:496-512.

97. Ehrenkranz NI, Alfonso BC. Failure of bland soap handwash to prevent hand transfer of patient bacteria to urethral catheters. Infect Control Hosp Epidemiol 1991;12:654-662.

98. Zaragoza M, Salles M, Gomez J, Bayas JM, Trilla A. Handwashing with soap or alcoholic solutions? a randomized clinical trial of its effectiveness. Am J Infect Control 1999;27:258-261.

99. Winnefeld M, Richard MA, Drancourt M, Grob JJ. Skin tolerance and effectiveness of two hand decontamination procedures in everyday hospital use. Br J Dermatol 2000;143:546550.

100. Girou E, Loyeau S, Legrand P, Oppein F, Brun-Buisson C. Efficacy of handrubbing with alcohol based solution versus standard handwashing with antiseptic soap: randomised clinical trial. BMJ 2002;325(7360):362.

101. Kac G, Podglajen I, Gueneret M, Vaupre S, Bissery A, Meyer G. Microbiological evaluation of two hand hygiene procedures achieved by healthcare workers during routine patient care: a randomized study. I Hosp Infect 2005;60:32-39.

102. Abaza AF, Amine AE, Hazzah WA. Comparative study on efficacy of different alcohol hand rubs and routine hand wash in a health-care setting, Alexandria, Egypt. J Egypt Public Health Assoc 2010;85(5-6):273-283.

103. Pickering AJ, Julian TR, Mamuya S, Boehm AB, Davis J. Bacterial hand contamination among Tanzanian mothers varies temporally and following household activities. Trop Med Int Health 2011;16:233-239.

104. Chow A, Arah OA, Chan SP, et al. Alcohol handrubbing and chlorhexidine handwashing protocols for routine hospital practice: a randomized clinical trial of protocol efficacy and time effectiveness. Am J Infect Control 2012;40:800-805.

105. Larson EL, Aiello AE, Bastyr J, et al. Assessment of two hand hygiene regimens for intensive care unit personnel. Crit Care Med 2001;29:944-951.

106. Bellamy K, Alcock R, Babb JR, Davies JG, Ayliffe GA. A test for the assessment of "hygienic" hand disinfection using rotavirus. J Hosp Infect 1993;24:201-210.

107. Sattar SA. Microbicides and the environmental control of nosocomial viral infections. J Hosp Infect 2004;56(suppl 2):S64S69.

108. Lages SL, Ramakrishnan MA, Goyal SM. In-vivo efficacy of hand sanitisers against feline calicivirus: a surrogate for norovirus. J Hosp Infect 2008;68:159-163.

109. Turner RB, Fuls JL, Rodgers ND. Effectiveness of hand sanitizers with and without organic acids for removal of rhinovirus from hands. Antimicrob Agents Chemother 2010;54:1363-1364.

110. Steinmann J, Paulmann D, Becker B, Bischoff B, Steinmann E, Steinmann J. Comparison of virucidal activity of alcoholbased hand sanitizers versus antimicrobial hand soaps in vitro and in vivo. J Hosp Infect 2012;82:277-280.

111. Davies JG, Babb JR, Bradley CR, Ayliffe GA. Preliminary study of test methods to assess the virucidal activity of skin disin- fectants using poliovirus and bacteriophages. J Hosp Infect 1993; 25:125-131.

112. Grayson ML, Melvani S, Druce J, et al. Efficacy of soap and water and alcohol-based hand-rub preparations against live H1N1 influenza virus on the hands of human volunteers. Clin Infect Dis 2009;48:285-291.

113. Liu P, Escudero B, Jaykus LA, et al. Laboratory evidence of norwalk virus contamination on the hands of infected individuals. Appl Environ Microbiol 2013;79:7875-7881.

114. Savolainen-Kopra C, Korpela T, Simonen-Tikka ML, et al. Single treatment with ethanol hand rub is ineffective against human rhinovirus - hand washing with soap and water removes the virus efficiently. J Med Virol 2012;84:543-547.

115. Mukherjee DV, Cohen B, Bovino ME, Desai S, Whittier S, Larson EL. Survival of influenza virus on hands and fomites in community and laboratory settings. Am J Infect Control 2012; 40:590-594.

116. Larson EL, Cohen B, Baxter KA. Analysis of alcohol-based hand sanitizer delivery systems: efficacy of foam, gel, and wipes against influenza A (H1N1) virus on hands. Am J Infect Control 2012;40:806-809.

117. Gould D, Drey N. Hand hygiene technique. Nurs Stand 2008; 22(34):42-46.

118. Smith SM. A review of hand-washing techniques in primary care and community settings. J Clin Nurs 2009;18:786-790.

119. Widmer AE, Dangel M. Alcohol-based handrub: evaluation of technique and microbiological efficacy with international infection control professionals. Infect Control Hosp Epidemiol 2004;25:207-209.

120. Widmer AF, Conzelmann M, Tomic M, Frei R, Stranden AM. Introducing alcohol-based hand rub for hand hygiene: the critical need for training. Infect Control Hosp Epidemiol 2007;28: 50-54.

121. Tschudin Sutter S, Frei R, Dangel M, Widmer AF. Effect of teaching recommended World Health Organization technique on the use of alcohol-based hand rub by medical students. Infect Control Hosp Epidemiol 2010;31:1194-1195.

122. Kampf G, Reichel M, Feil Y, Eggerstedt S, Kaulfers PM. Influence of rub-in technique on required application time and hand coverage in hygienic hand disinfection. BMC Infect Dis 2008;8:149.

123. Taylor LJ. An evaluation of handwashing techniques-1. Nurs Times 1978;74:54-55.

124. Longtin Y, Sax H, Allegranzi B, Schneider F, Pittet D. Videos in clinical medicine: hand hygiene. $N$ Engl J Med 2011;364:e24.

125. Macinga DR, Edmonds SL, Campbell E, Shumaker DJ, Arbogast JW. Efficacy of novel alcohol-based hand rub products at typical in-use volumes. Infect Control Hosp Epidemiol 2013;34:299-301.

126. Kampf G, Marschall S, Eggerstedt S, Ostermeyer C. Efficacy of ethanol-based hand foams using clinically relevant amounts: a cross-over controlled study among healthy volunteers. $B M C$ Infect Dis 2010;10:78.

127. Kampf G, Ruselack S, Eggerstedt S, Nowak N, Bashir M. Less and less-influence of volume on hand coverage and bactericidal efficacy in hand disinfection. BMC Infect Dis 2013;13: 472.

128. Larson E, Friedman C, Cohran J, Treston-Aurand J, Green S. Prevalence and correlates of skin damage on the hands of nurses. Heart Lung 1997;26:404-412. 
129. Larson E, Girard R, Pessoa-Silva CL, Boyce J, Donaldson L, Pittet $\mathrm{D}$. Skin reactions related to hand hygiene and selection of hand hygiene products. Am J Infect Control 2006;34:627635.

130. Chamorey E, Marcy P-Y, Dandine M, et al. A prospective multicenter study evaluating skin tolerance to standard hand hygiene techniques. Am I Infect Control 2011;39:6-13.

131. Stutz N, Becker D, Jappe U, et al. Nurses' perceptions of the benefits and adverse effects of hand disinfection: alcohol-based hand rubs vs. hygienic handwashing: a multicentre questionnaire study with additional patch testing by the German contact dermatitis research group. $\mathrm{Br} J$ Dermatol 2009;160:565-572.

132. Dulon M, Pohrt U, Skudlik C, Nienhaus A. Prevention of occupational skin disease: a workplace intervention study in geriatric nurses. Br I Dermatol 2009;161:337-344.

133. Houben E, DePaepe K, Rogiers V. Skin condition associated with intensive use of alcoholic gels for hand disinfection: a combination of biophysical and sensorial data. Contact Dermatitis 2006;54:261-267.

134. Boyce JM, Pittet D; Society for Healthcare Epidemiology of America, Association for Professionals in Infection Control, Infectious Diseases Society of America. Guideline for Hand Hygiene in Health-Care Settings: Recommendations of the Healthcare Infection Control Practices Advisory Committee and the HICPAC/SHEA/APIC/IDSA Hand Hygiene Task Force. MMWR Recomm Rep 2002;51(RR-16):1-45.

135. Ahmed-Lecheheb D, Cunat L, Hartemann P, Hautemaniere A. Prospective observational study to assess hand skin condition after application of alcohol-based hand rub solutions. Am J Infect Control 2012;40:160-164.

136. Larson EL, Cimiotti J, Haas J, et al. Effect of antiseptic handwashing vs alcohol sanitizer on health care-associated infection in neonatal intensive care units. Arch Pediatr Adolesc Med 2005; 159:377-383.

137. Kampf G, Wigger-Alberti W, Wilhelm K-P. Do atopics tolerate alcohol-based hand rubs? a prospective, controlled, randomized double-blind clinical trial. Acta Derm Venereol 2006;86: $140-143$

138. Ohlenschlaeger J, Friberg J, Ramsing D, Agner T. Temperature dependency of skin susceptibility to water and detergents. Acta Derm Venereol 1996;76:274-276.

139. Williams C, Wilkinson SM, McShane P, et al. A double-blind, randomized study to assess the effectiveness of different moisturizers in preventing dermatitis induced by hand washing to simulate healthcare use. Br J Dermatol 2010;162:1108-1192.

140. Ibler KS, Jebec GBE, Diepgen TL, et al. Skin care education and individual counselling versus treatment as usual in healthcare workers with hand eczema: randomised clinical trial. $B M J$ 2012;345(e7822):1-14.

141. Jungbauer FH, Steenstra FB, Groothoff JW, Coenraads PJ. Characteristics of wet work in nurses. Int Arch Occup Environ Health 2005;78:248-251.

142. Cimiotti JP, Marmur ES, Nesin M, Hamlin-Cook PH, Larson EL. Adverse reactions associated with an alcohol-based hand antiseptic among nurses in a neonatal intensive care unit. Am $J$ Infect Control 2003;31:43-48.

143. Boyce JM, Pearson ML. Low frequency of fires from alcoholbased hand rub dispensers in healthcare facilities. Infect Control Hosp Epidemiol 2003;24:618-619.

144. Kramer A, Kampf G. Hand rub-associated fire incidents during
25,038 hospital-years in Germany. Infect Control Hosp Epidemiol 2007;28:745-746.

145. WHO Clean Care Is Safer Care. Glove use information leaflet. http://www.who.int/gpsc/5may/Glove_Use_Information Leaflet.pdf. Accessed August 12, 2013.

146. Johnson S, Gerding DN, Olson MM, et al. Prospective, controlled study of vinyl glove use to interrupt Clostridium difficile nosocomial transmission. Am J Med 1990;88:137-140.

147. Tenorio AR, Badri SM, Sahgal NB, et al. Effectiveness of gloves in the prevention of hand carriage of vancomycin-resistant Enterococcus species by health care workers after patient care. Clin Infect Dis 2001;32:826-829.

148. Olsen RJ, Lynch P, Coyle MB, Cummings J, Bokete T, Stamm WE. Examination gloves as barriers to hand contamination in clinical practice. JAMA 1993;270:350-353.

149. Pessoa-Silva CL, Dharan S, Hugonnet S, et al. Dynamics of bacterial hand contamination during routine neonatal care. Infect Control Hosp Epidemiol 2004;25:192-197.

150. Duckro AN, Blom DW, Lyle EA, Weinstein RA, Hayden MK. Transfer of vancomycin-resistant enterococci via health care worker hands. Arch Intern Med 2005;165:302-307.

151. Guerrero DM, Nerandzic MM, Jury LA, Jinno S, Chang S, Donskey CJ. Acquisition of spores on gloved hands after contact with the skin of patients with Clostridium difficile infection and with environmental surfaces in their rooms. Am I Infect Control 2012;40:556-558.

152. Rossoff LJ, Lam S, Hilton E, Borenstein M, Isenberg HD. Is the use of boxed gloves in an intensive care unit safe? Am J Med 1993;94:602-607.

153. Hughes KA, Cornwall J, Theis JC, Brooks HI. Bacterial contamination of unused, disposable non-sterile gloves on a hospital orthopaedic ward. Australas Med J 2013;6:331-338.

154. Rossoff LJ, Borenstein M, Isenberg HD. Is hand washing really needed in an intensive care unit? Crit Care Med 1995;23:12111216.

155. Rock C, Harris AD, Reich NG, Johnson JK, Thom KA. Is hand hygiene before putting on nonsterile gloves in the intensive care unit a waste of health care worker time? a randomized controlled trial. Am J Infect Control 2013;41:994-996.

156. Aiello AE, Larson EL, Levy SB. Consumer antibacterial soaps: effective or just risky? Clin Infect Dis 2007;45(suppl 2):S137S147.

157. Perencevich EN, Wong MT, Harris AD. National and regional assessment of the antibacterial soap market: a step toward determining the impact of prevalent antibacterial soaps. Am I Infect Control 2001;29:281-283.

158. Proposed Amendment to 1994 Tentative Final Monograph on December 17, 2013. https://www.federalregister.gov/articles /2013/12/17/2013-29814/safety-and-effectiveness-of-consumer -antiseptics-topical-antimicrobial-drug-products-for. Accessed December 18, 2013.

159. Bergstrom KG. Update on antibacterial soaps: the FDA takes a second look at triclosans. J Drugs Dermatol 2014;13:501-503.

160. Webster J, Faoagali JL, Cartwright D. Elimination of methicillin-resistant Staphylococcus aureus from a neonatal intensive care unit after hand washing with triclosan. I Paediatr Child Health 1994;30:59-64.

161. Zafar AB, Butler RC, Reese DJ, Gaydos LA, Mennonna PA. Use of $0.3 \%$ triclosan (Bacti-Stat) to eradicate an outbreak of 
methicillin-resistant Staphylococcus aureus in a neonatal nursery. Am J Infect Control 1995;23:200-208.

162. Jones RD, Jampani HB, Newman JL, Lee AS. Triclosan: a review of effectiveness and safety in health care settings. Am J Infect Control 2000;28:184-196.

163. Capretti MG, Sandri F, Tridapalli E, Galletti S, Petracci E, Faldella $G$. Impact of a standardized hand hygiene program on the incidence of nosocomial infection in very low birth weight infants. Am J Infect Control 2008;36:430-435.

164. Drury B, Scott J, Rosi-Marshall EJ, Kelly JJ. Triclosan exposure increases triclosan resistance and influences taxonomic composition of benthic bacterial communities. Environ Sci Technol 2013;47:8923 -8930 .

165. D'Arezzo S, Lanini S, Puro V, Ippolito G, Visca P. High-level tolerance to triclosan may play a role in Pseudomonas aeruginosa antibiotic resistance in immunocompromised hosts: evidence from outbreak investigation. BMC Res Notes 2012;5:43.

166. Syed AK, Ghosh S, Love NG, Boles BR. Triclosan promotes Staphylococcus aureus nasal colonization. MBio 2014;5:e01015.

167. Perron MM, Ho KT, Cantwell MG, Burgess RM, Pelletier MC. Effects of triclosan on marine benthic and epibenthic organisms. Environ Toxicol Chem 2012;31:1861-1866.

168. Calafat AM, Ye X, Wong LY, Reidy JA, Needham LL. Urinary concentrations of triclosan in the U.S. population: 2003-2004. Environ Health Perspect 2008;116:303-307.

169. Koeppe ES, Ferguson KK, Colacino JA, Meeker JD. Relationship between urinary triclosan and paraben concentrations and serum thyroid measures in NHANES 2007-2008. Sci Total Environ 2013;445-446:299-305.

170. Lankester J, Patel C, Cullen MR, Ley C, Parsonnet J. Urinary triclosan is associated with elevated body mass index in NHANES. PLOS ONE 2013;8:e80057.

171. Clayton EM, Todd M, Dowd JB, Aiello AE. The impact of bisphenol $A$ and triclosan on immune parameters in the U.S. population, NHANES 2003-2006. Environ Health Perspect 2011;119:390-396.

172. Halden RU. On the need and speed of regulating triclosan and triclocarban in the United States. Environ Sci Technol 2014;48: 3603-3611.

173. Park GW, Barclay L, Macinga D, Charbonneau D, Pettigrew CA, Vinje J. Comparative efficacy of seven hand sanitizers against murine norovirus, feline calicivirus, and GII.4 norovirus. J Food Prot 2010;73:2232-2238.

174. Kampf G, Grotheer D, Steinmann J. Efficacy of three ethanolbased hand rubs against feline calicivirus, a surrogate virus for norovirus. J Hosp Infect 2005;60:144-149.

175. Macinga DR, Sattar SA, Jaykus LA, Arbogast JW. Improved inactivation of nonenveloped enteric viruses and their surrogates by a novel alcohol-based hand sanitizer. Appl Environ Microbiol 2008;74:5047-5052.

176. Gehrke C, Steinmann J, Goroncy-Bermes P. Inactivation of feline calicivirus, a surrogate of norovirus (formerly Norwalklike viruses), by different types of alcohol in vitro and in vivo. J Hosp Infect 2004;56:49-55.

177. Kramer A, Galabov AS, Sattar SA, et al. Virucidal activity of a new hand disinfectant with reduced ethanol content: comparison with other alcohol-based formulations. I Hosp Infect 2006;62:98-106.

178. Dubberke ER, Gerding DN, Classen D, et al. Strategies to pre- vent Clostridium difficile infections in acute care hospitals. Infect Control Hosp Epidemiol 2008;29(suppl 1):S81-S92.

179. Jabbar U, Leischner J, Kasper D, et al. Effectiveness of alcoholbased hand rubs for removal of Clostridium difficile spores from hands. Infect Control Hosp Epidemiol 2010;31:565-570.

180. Oughton MT, Loo VG, Dendukuri N, Fenn S, Libman MD. Hand hygiene with soap and water is superior to alcohol rub and antiseptic wipes for removal of Clostridium difficile. Infect Control Hosp Epidemiol 2009;30:939-944.

181. Edmonds SL, Zapka C, Kasper D, et al. Effectiveness of hand hygiene for removal of Clostridium difficile spores from hands. Infect Control Hosp Epidemiol 2013;34:302-305.

182. Landelle $C$, Verachten M, Legrand P, Girou E, Barbut F, Buisson CB. Contamination of healthcare workers' hands with Clostridium difficile spores after caring for patients with $C$. difficile infection. Infect Control Hosp Epidemiol 2014;35:10-15.

183. CDC Vital Signs. Stopping C. difficile infections. http://www .cdc.gov/VitalSigns/Hai/StoppingCdifficile/. Published 2012. Accessed May 15, 2013.

184. Stone SP, Fuller C, Savage J, et al. Evaluation of the national Cleanyourhands campaign to reduce Staphylococcus aureusbacteraemia and Clostridium difficile infection in hospitals in England and Wales by improved hand hygiene: four year, prospective, ecological, interrupted time series study. BMJ 2012; 344:e3005.

185. Rupp ME, Fitzgerald T, Puumala $S$, et al. Prospective, controlled, cross-over trial of alcohol-based hand gel in critical care units. Infect Control Hosp Epidemiol 2008;29:8-15.

186. Vernaz N, Sax H, Pittet D, Bonnabry P, Schrenzel J, Harbarth $\mathrm{S}$. Temporal effects of antibiotic use and hand rub consumption on the incidence of MRSA and Clostridium difficile. I Antimicrob Chemother 2008;62:601-607.

187. Gordin FM, Schultz ME, Huber RA, Gill JA. Reduction in nosocomial transmission of drug-resistant bacteria after introduction of an alcohol-based handrub. Infect Control Hosp Epidemiol 2005;26:650-653.

188. Widmer AF, Rotter M, Voss A, et al. Surgical hand preparation: state-of-the-art. J Hosp Infect 2010;74:112-122.

189. Shen NJ, Pan SC, Sheng WH, et al. Comparative antimicrobial efficacy of alcohol-based hand rub and conventional surgical. scrub in a medical center. $J$ Microbiol Immunol Infect. doi: 10.1016/j.jmii.2013.08.005. Electronically published September 21, 2013.

190. Carro C, Camilleri L, Traore O, et al. An in-use microbiological comparison of two surgical hand disinfection techniques in cardiothoracic surgery: hand rubbing versus hand scrubbing. J Hosp Infect 2007;67:62-66.

191. Tavolacci MP, Pitrou I, Merle V, Haghighat S, Thillard D, Czernichow P. Surgical hand rubbing compared with surgical hand scrubbing: comparison of efficacy and costs. J Hosp Infect 2006; 63:55-59.

192. Parienti JJ, Thibon P, Heller R, et al. Hand-rubbing with an aqueous alcoholic solution vs traditional surgical hand-scrubbing and 30-day surgical site infection rates: a randomized equivalence study. JAMA 2002;288:722-727.

193. Gupta C, Czubatyj AM, Briski LE, Malani AK. Comparison of two alcohol-based surgical scrub solutions with an iodinebased scrub brush for presurgical antiseptic effectiveness in a community hospital. J Hosp Infect 2007;65:65-71.

194. Tanner J, Swarbrook S, Stuart J. Surgical hand antisepsis to 
reduce surgical site infection. Cochrane Database Syst Rev 2008; (1):CD004288.

195. Weight CJ, Lee MC, Palmer JS. Avagard hand antisepsis vs. traditional scrub in 3600 pediatric urologic procedures. Urology 2010;76:15-17.

196. Haessler S, Connelly NR, Kanter G, et al. A surgical site infection cluster: the process and outcome of an investigationthe impact of an alcohol-based surgical antisepsis product and human behavior. Anesth Analg 2010;110:1044-1048.

197. di Martino P, Ban KM, Bartoloni A, Fowler KE, Saint S, Mannelli F. Assessing the sustainability of hand hygiene adherence prior to patient contact in the emergency department: a 1-year postintervention evaluation. Am J Infect Control 2011;39:1418.

198. Blanchard JBR, Bjerke N, Boylard E, Graves P. Recommended practices for hand hygiene in the perioperative setting in perioperative standards and recommended practices, 2013 edition. AORN 2013:66-67.

199. Moolenaar RL, Crutcher JM, San Joaquin VH, et al. A prolonged outbreak of Pseudomonas aeruginosa in a neonatal intensive care unit: did staff fingernails play a role in disease transmission? Infect Control Hosp Epidemiol 2000;21:80-85.

200. Gupta A, Della-Latta P, Todd B, et al. Outbreak of extendedspectrum $\beta$-lactamase-producing Klebsiella pneumoniae in a neonatal intensive care unit linked to artificial nails. Infect Control Hosp Epidemiol 2004;25:210-215.

201. Tanner J, Khan D, Walsh S, Chernova J, Lamont S, Laurent T. Brushes and picks used on nails during the surgical scrub to reduce bacteria: a randomised trial. $J$ Hosp Infect 2009;71(3): 234-238.

202. Okgün Alcan A, Demir Korkmaz F. Comparison of the efficiency of nail pick and brush used for nail cleaning during surgical scrub on reducing bacterial counts. Am J Infect Control 2012;40(9):826-829.

203. Facility Guidelines Institute. 2010 guidelines. http://www .fgiguidelines.org/guidelines2010.php. Accessed April 3, 2014.

204. Hanenkamp N. The process model for shop floor management implementation. Adv Ind Eng Manag 2013;2:40-46.

205. Larson E, Girard R, Pessoa-Silva CL, Boyce J, Donaldson L, Pittet D. Skin reactions related to hand hygiene and selection of hand hygiene products. Am J Infect Control 2006;34:627635.

206. Hayden MK, Blom DW, Lyle EA, Moore CG, Weinstein RA. Risk of hand or glove contamination after contact with patients colonized with vancomycin-resistant Enterococcus or the colonized patients' environment. Infect Control Hosp Epidemiol 2008;29:149-154.

207. Wendt C, Knautz D, von Baum H. Differences in hand hygiene behavior related to the contamination risk of healthcare activities in different groups of healthcare workers. Infect Control Hosp Epidemiol 2004;25:203-206.

208. Rodriguez EM, Parrott C, Rolka H, Monroe SS, Dwyer DM. An outbreak of viral gastroenteritis in a nursing home: importance of excluding ill employees. Infect Control Hosp Epidemiol 1996;17:587-592.

209. Standaert SM, Hutcheson RH, Schaffner W. Nosocomial transmission of Salmonella gastroenteritis to laundry workers in a nursing home. Infect Control Hosp Epidemiol 1994;15:22-26.

210. Eggimann P, Harbarth S, Constantin MN, Touveneau S, Chevrolet JC, Pittet $\mathrm{D}$. Impact of a prevention strategy targeted at vascular-access care on incidence of infections acquired in intensive care. Lancet 2000;355(9218):1864-1868.

211. Hirschmann H, Fux L, Podusel J, et al. The influence of hand hygiene prior to insertion of peripheral venous catheters on the frequency of complications. J Hosp Infect 2001;49:199-203.

212. Lucet JC, Rigaud MP, Mentre F, et al. Hand contamination before and after different hand hygiene techniques: a randomized clinical trial. $J$ Hosp Infect 2002;50:276-280.

213. Ejemot RI, Ehiri JE, Meremikwu MM, Critchley JA. Hand washing for preventing diarrhoea. Cochrane Database Syst Rev 2008;(1):CD004265.

214. Luby SP, Agboatwalla M, Painter J, Altaf A, Billhimer WL, Hoekstra RM. Effect of intensive handwashing promotion on childhood diarrhea in high-risk communities in Pakistan: a randomized controlled trial. JAMA 2004;291:2547-2554.

215. Ray AJ, Hoyen CK, Taub TF, Eckstein EC, Donskey CJ. Nosocomial transmission of vancomycin-resistant enterococci from surfaces. JAMA 2002;287:1400-1401.

216. Bhalla A, Pultz NJ, Gries DM, et al. Acquisition of nosocomial pathogens on hands after contact with environmental surfaces near hospitalized patients. Infect Control Hosp Epidemiol 2004; 25:164-167.

217. Larson E. A causal link between handwashing and risk of infection? examination of the evidence. Infect Control Hosp Epidemiol 1988;9:28-36.

218. Carrico RM, Rebmann T, English JF, Mackey J, Cronin SN. Infection prevention and control competencies for hospitalbased health care personnel. Am J Infect Control 2008;36:691701.

219. Milward MR, Cooper PR. Competency assessment for infection control in the undergraduate dental curriculum. Eur J Dent Educ 2007;11:148-154.

220. Garcia-Williams A, Brinsley-Rainisch K, Schillie S, SinkowitzCochran R. To ask or not to ask? the results of a formative assessment of a video empowering patients to ask their health care providers to perform hand hygiene. J Patient Saf 2010;6: 80-85.

221. Jenner EA, Jones F, Fletcher BC, Miller L, Scott GM. Hand hygiene posters: selling the message. J Hosp Infect 2005;59:7782.

222. Erasmus V, Brouwer W, van Beeck EF, et al. A qualitative exploration of reasons for poor hand hygiene among hospital workers: lack of positive role models and of convincing evidence that hand hygiene prevents cross-infection. Infect Control Hosp Epidemiol 2009;30:415 419.

223. Ivers N, Jamtvedt G, Flottorp S, et al. Audit and feedback: effects on professional practice and healthcare outcomes. Cochrane Database Syst Rev 2012;6:CD000259.

224. Muller MP, Detsky AS. Public reporting of hospital hand hygiene compliance--helpful or harmful? JAMA 2010;304:11161117.

225. Hugonnet S, Perneger TV, Pittet D. Alcohol-based handrub improves compliance with hand hygiene in intensive care units. Arch Intern Med 2002;162:1037-1043.

226. Harbarth S, Pittet D, Grady L, et al. Interventional study to evaluate the impact of an alcohol-based hand gel in improving hand hygiene compliance. Pediatr Infect Dis J 2002;21:489-495.

227. Aboumatar H, Ristaino $\mathrm{P}$, Davis RO, et al. Infection prevention promotion program based on the PRECEDE model: improving 
hand hygiene behaviors among healthcare personnel. Infect Control Hosp Epidemiol 2012;33:144-151.

228. Brown SM, Lubimova AV, Khrustalyeva NM, et al. Use of an alcohol-based hand rub and quality improvement interventions to improve hand hygiene in a Russian neonatal intensive care unit. Infect Control Hosp Epidemiol 2003;24:172-179.

229. Helder OK, Brug J, Looman CW, van Goudoever JB, Kornelisse RF. The impact of an education program on hand hygiene compliance and nosocomial infection incidence in an urban neonatal intensive care unit: an intervention study with before and after comparison. Int J Nurs Stud 2010;47:1245-1252.

230. Talbot TR, Johnson JG, Fergus C, et al. Sustained improvement in hand hygiene adherence: utilizing shared accountability and financial incentives. Infect Control Hosp Epidemiol 2013;34: 1129-1136.

231. Jang JH, Wu S, Kirzner D, et al. Focus group study of hand hygiene practice among healthcare workers in a teaching hospital in Toronto, Canada. Infect Control Hosp Epidemiol 2010; 31:144-150.

232. Zerr DM, Allpress AL, Heath J, Bornemann R, Bennett E. Decreasing hospital-associated rotavirus infection: a multidisciplinary hand hygiene campaign in a children's hospital. Pediatr Infect Dis J 2005;24:397-403.

233. Bischoff WE, Reynolds TM, Sessler CN, Edmond MB, Wenzel RP. Handwashing compliance by health care workers: the impact of introducing an accessible, alcohol-based hand antiseptic. Arch Intern Med 2000;160:1017-1021.

234. Doron SI, Kifuji K, Hynes BT, et al. A multifaceted approach to education, observation, and feedback in a successful hand hygiene campaign. Jt Comm J Qual Patient Saf 2011;37:3-10.

235. Tromp M, Huis A, de Guchteneire I, et al. The short-term and long-term effectiveness of a multidisciplinary hand hygiene improvement program. Am I Infect Control 2012;40:732-736.

236. Monistrol O, Calbo E, Riera M, et al. Impact of a hand hygiene educational programme on hospital-acquired infections in medical wards. Clin Microbiol Infect 2012;18:1212-1218.

237. Mathai E, Allegranzi B, Seto WH, et al. Educating healthcare workers to optimal hand hygiene practices: addressing the need. Infection 2010;38:349-356.

238. Pessoa-Silva CL, Hugonnet S, Pfister R, et al. Reduction of health care associated infection risk in neonates by successful hand hygiene promotion. Pediatrics 2007;120:e382-e390.

239. Girard R, Amazian K, Fabry J. Better compliance and better tolerance in relation to a well-conducted introduction to rubin hand disinfection. $J$ Hosp Infect 2001;47:131-137.

240. Maury E, Alzieu M, Baudel JL, et al. Availability of an alcohol solution can improve hand disinfection compliance in an intensive care unit. Am I Respir Crit Care Med 2000;162:324327.

241. Allegranzi B, Sax H, Bengaly L, et al. Successful implementation of the World Health Organization hand hygiene improvement strategy in a referral hospital in Mali, Africa. Infect Control Hosp Epidemiol 2010;31:133-141.

242. Santana SL, Furtado GH, Coutinho AP, Medeiros EA. Assessment of healthcare professionals' adherence to hand hygiene after alcohol-based hand rub introduction at an intensive care unit in São Paulo, Brazil. Infect Control Hosp Epidemiol 2007; 28:365-367.

243. Caniza MA, Duenas L, Lopez B, et al. A practical guide to alcohol-based hand hygiene infrastructure in a resource-poor pediatric hospital. Am J Infect Control 2009;37:851-854.

244. Grant AM, Hofmann DA. It's not all about me: motivating hand hygiene among health care professionals by focusing on patients. Psychol Sci 2011;22:1494-1499.

245. Larson EL, Patel SJ, Evans D, Saiman L. Feedback as a strategy to change behaviour: the devil is in the details. J Eval Clin Pract 2013;19:230-234.

246. Dubbert PM, Dolce J, Richter W, Miller M, Chapman SW. Increasing ICU staff handwashing: effects of education and group feedback. Infect Control Hosp Epidemiol 1990;11:191193.

247. Rosenthal VD, McCormick RD, Guzman S, Villamayor C, Orellano PW. Effect of education and performance feedback on handwashing: the benefit of administrative support in Argentinean hospitals. Am J Infect Control. 2003;31:85-92.

248. The Joint Commission. Measuring Hand Hygiene Adherence: Overcoming the Challenges. Oakbrook Terrace, IL: The Joint Commission, 2009.

249. Pugh M, Reinertsen J. Reducing harm to patients: using patient safety dashboards at the board level. Healthe Exec 2007;22:62, 64-65.

250. Sellick JA Jr. The use of statistical process control charts in hospital epidemiology. Infect Control Hosp Epidemiol 1993;14: 649-656.

251. Al-Tawfiq JA, Abed MS, Al-Yami N, Birrer RB. Promoting and sustaining a hospital-wide, multifaceted hand hygiene program resulted in significant reduction in health care-associated infections. Am J Infect Control 2013;41:482-486.

252. Hilburn J, Hammond BS, Fendler EJ, Groziak PA. Use of alcohol hand sanitizer as an infection control strategy in an acute care facility. Am J Infect Control 2003;31:109-116.

253. Pittet D. Improving adherence to hand hygiene practice: a multidisciplinary approach. Emerg Infect Dis 2001;7:234-240.

254. Schweon SJ, Edmonds SL, Kirk J, Rowland DY, Acosta C. Effectiveness of a comprehensive hand hygiene program for reduction of infection rates in a long-term care facility. Am.J Infect Control 2013;41:39-44.

255. Institute for Healthcare Improvement. How to Guide: Hand Hygiene Improvement; A Guide for Improving Practices among. Health Care Workers. Cambridge, MA: Institute for Healthcare Improvement, 2006. http://www.ihi.org/resources/Pages/Tools /HowtoGuideImprovingHandHygiene.aspx. Accessed December 23, 2013.

256. Jenner EA, Fletcher BC, Watson P, Jones FA, Miller L, Scott GM. Discrepancy between self-reported and observed hand hygiene behaviour in healthcare professionals. J Hosp Infect 2006;63:418-422.

257. Guyatt GH, Oxman AD, Vist GE, et al. GRADE: an emerging consensus on rating quality of evidence and strength of recommendations. BMJ 2008;336(7650):924-926.

258. GRADE. Canadian Task Force on Preventive Health Care website. http://canadiantaskforce.ca/methods/grade/. Accessed December 31, 2013. 